\title{
UM SISTEMA DE INFERÊNCIA NEBULOSO PARA APOIO A TOMADA DE DECISÃO DO ANALISTA DE CRÉDITO DE EMPRESAS DE CRÉDITO PESSOAL
}

\author{
Paulo Soares Barreto Filho ${ }^{1}$, Maria Augusta Soares Machado ${ }^{2}$, Valéria Zuma \\ Medeiros $^{3}$ \\ ${ }^{1,2}$ Faculdades IBMEC, Av Rio Branco n ${ }^{\circ}$ 108, $9^{\circ}$ andar, Centro, Rio de Janeiro, RJ, Brasil. \\ mmachado@ibmecri.br \\ ${ }^{3}$ Universidade Federal Fluminense, Instituto de Matemática, Depto Matemática Aplicada, Rua \\ Mário Santos Braga, s/n, Valonguinho, Niterói, RJ, Brasil. \\ valeria zuma@yahoo.com.br
}

\begin{abstract}
Resumo
O analista de crédito tem como tarefa analisar o perfil de um cliente, com o objetivo de emitir um parecer sobre sua situação e então decidir se este merece ou não o crédito solicitado. Analisando o perfil desse cliente em potencial, é possível ter bons indicadores se será um bom pagador, ou se será um cliente inadimplente. Com a intenção de auxiliar o analista de crédito de empresas especializadas em crédito pessoal, este trabalho tem o objetivo de implementar e avaliar uma metodologia, usando conceitos de matemática nebulosa, inteligência computacional e um banco de dados como fonte de conhecimento.
\end{abstract}

Palavras-chave: Crédito pessoal, inadimplência, matemática nebulosa.

\begin{abstract}
The word credit can have different meanings and uses. Credit can mean trust and it can be defined as the act of disposing a determined value on behalf of another with the promise of receiving this value in the future. Financial institution, may have this disposal as one of their objective, in other words, they may dispose values to their clients in exchange for a future payment. This paper presents a methodology using data mining and fuzzy inference systems to be used by a credit analyst to minimize inadimplence risk.
\end{abstract}

Key-words: Personal credit, inadimplence, fuzzy logic.

\section{Introdução}

Toda vez que uma empresa resolve conceder crédito a um cliente seja ela uma pequena loja de bairro, uma mercearia, um banco ou uma empresa especializada em conceder crédito, é feita uma análise da situação desse cliente, pessoa física ou jurídica, para tentar identificar se será ou não um cliente inadimplente. Assim, como as empresas que concedem crédito, seus métodos de análise e clientes são bem diferentes. Os métodos utilizados para analisar um futuro cliente vão desde simples confiança, verificação de sua situação financeira atual, consulta a bancos e empresas que possuam seu cadastro até métodos computacionais e sistemas especializados em análise de crédito.

Como em algumas empresas especializadas a análise de credito é fundamental para a sobrevivência do negócio, este trabalho propõe uma nova metodologia para analisar 0 problema. Este trabalho propõe um sistema baseado em conceitos de lógica nebulosa para tentar tornar a tarefa de analisar o perfil do cliente mais rápida, correta e eficaz, tentando diminuir o nível de inadimplência da empresa.

Crédito é uma palavra que possui vários significados e usos, pode significar confiança, boa reputação ou boa fama. Também podemos definila como o ato de disponibilizar uma quantia em dinheiro a um terceiro, com a promessa de pagamento futuro, acrescido de juros ou não. No comércio, o crédito facilita a venda de mercadorias, permitindo que os clientes comprem, levem a mercadoria no ato e paguem em parcelas. Essa modalidade é chamada de crédito direto ao consumidor. Desta forma, algumas empresas conseguem obter um 
resultado financeiro melhor (ganho com 0 parcelamento das vendas) do que o resultado operacional (ganho com a venda de mercadorias), por causa do valor das taxas de juros cobradas. Na indústria, como no comércio, o crédito facilita a compra de equipamentos, matéria-prima e produtos manufaturados, fazendo com que o número de compradores potencias aumentem. Nos bancos é uma das vertentes de seu negócio básico, a intermediação financeira. $O$ banco capta dinheiro com clientes que têm recursos disponíveis e os repassa aos tomadores de recursos em forma de empréstimo, assim, seu lucro é obtido com a diferença entre o que ele recebe do tomador e quanto ele paga do aplicador/investidor.

Em todas as modalidades de crédito e em todas as empresas que trabalham direta ou indiretamente com crédito, existe uma política que norteia toda operação. Nesta política, basicamente devem ser definidos a quem e de que modo será feita a concessão e que quantia será concedida a um, ou a um grupo, de indivíduos.

O processo de concessão de crédito para pessoas físicas ou jurídicas é muito parecido, todos têm um fluxograma bem semelhante. A pessoa física tem sua fonte de renda e suas despesas que podem ser de curto ou longo prazo. Ela tem que tentar fazer com que sua receita seja suficiente para honrar suas despesas. Muitas vezes, a falta de controle, o surgimento de despesas imprevistas ou outros fatores fazem com que exista a necessidade de se buscar um suprimento de dinheiro extra para preencher uma lacuna em seu orçamento. Nesta situação, é que surge o profissional de crédito com a missão de analisar se esse proponente merece que a empresa/instituição conceda a ele os recursos de que necessita. Há também a situação do proponente estar procurando recursos para investimento. Neste caso, a análise é feita de maneira um pouco diferente, mas os princípios são os mesmos.

A análise de crédito consiste em atribuir valores a um conjunto de fatores que permitam a emissão de um parecer sobre determinada operação de crédito. Para cada fator individual é emitido um valor subjetivo (positivo ou negativo). Se o conjunto de fatores apresentar valores positivos em maior número do que os negativos, a tendência é de que o parecer seja favorável à concessão do crédito, senão o analista não deve concedê-lo.

Existem diversos fatores que são utilizados na análise, como caráter e capacidade, e analisando esses fatores é possível emitir um parecer. Os fatores possibilitam uma idéia do provável comportamento do cliente, ou seja, analisando seu passado, tenta-se prever seu comportamento futuro, tentando assim só conceder crédito aos que demonstrem maiores e melhores chances de honrar seus compromissos. Por isso, outro fator de vital importância nessa análise são as garantias. Apesar de uma operação de crédito não dever ser baseada somente nas garantias, esse é um fator fundamental na análise do crédito, pois ele pode dar a certeza de que, no caso de um sinistro, nosso capital investido retornará mais rápido [3].

De acordo com o que foi descrito, todas as empresas que, de alguma forma, emprestam dinheiro aos seus clientes, fazem uma análise prévia de seu perfil, sejam eles uma empresa ou uma pessoa física. Essa análise pode ser baseada em simples conhecimento pessoal, ou seja, apenas na confiança, ou pode se valer de um longo estudo sobre sua situação financeira. Com o intuito de auxiliar o analista no momento da concessão do crédito, este trabalho pretende apresentar uma nova metodologia, a fim de facilitar o trabalho desse analista, além de tornálo menos impreciso e totalmente imparcial.

\section{Matemática Nebulosa}

$\mathrm{Na}$ metade da década de 60 , começou a ser desenvolvida uma nova teoria com o objetivo de tornar o desenvolvimento e a análise de problemas complexos de controle mais tratáveis. Essa nova teoria foi proposta pelo professor Lotfi Zadeh, em artigo publicado em 1965. Zadeh, professor de engenharia elétrica e ciências da computação na Universidade de Berkeley observou que as regras que muitas pessoas usavam para fazer inferências eram inconsistentes, ou seja, essas pessoas não conseguiam explicar as regras que elas próprias usavam [6]. Como exemplo pode-se citar o fato de muitas vezes, simplesmente olhando para uma pessoa desconhecida, ser possível dizer quantos anos ela tem, qual o seu peso, altura, etc. Se questionados sobre quais as regras foram utilizadas para chegar a essas conclusões, não haveria uma resposta clara e objetiva, pois se chega a essas conclusões utilizando apenas a intuição. Assim, a grande contribuição dessa nova teoria é a possibilidade de capturar, em um modelo matemático clássico, conceitos intuitivos [13].

Toda essa metodologia, apresentada por Zadeh em 1965, ficou conhecida como Fuzzy Logic. Como toda nova idéia, essa também foi bastante criticada no início, sendo depois bem aceita por engenheiros e cientistas da computação [6]. Assim, a nova metodologia foi sendo utilizada em diversos países e, em cada um, teve seu nome modificado de acordo com a língua oficial. Em Portugal, é chamada de Lógica Nebulosa [3], em espanhol também foi traduzida como Lógica Nebulosa ou Lógica Borrosa (Ley, 2000). Em francês a nomenclatura utilizada é théorie des sous-ensembles flous (Kaufmann A., 
1973). Já em Português, temos duas denominações bastante utilizadas: Lógica Difusa [13] e Lógica Nebulosa [4]. Neste trabalho, adotar-se-á a terminologia Lógica Nebulosa.

Um bom exemplo para ilustrar o conceito de lógica nebulosa é o problema dos três copos [13]. Convidados a descrever a situação dos três recipientes mostrados na figura abaixo, utilizando apenas os predicados CHEIO e VAZIO, como deveria ser descrita a condição do recipiente do meio?

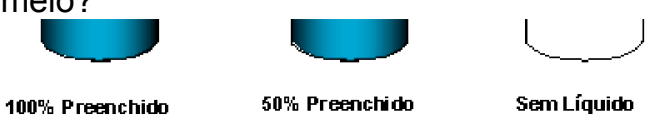

Figura 1 - O problema dos três copos

Afinal, o recipiente do meio está CHEIO ou VAZIO? $\mathrm{Na}$ verdade, pode ser dito que o recipiente está meio $\mathrm{CHEIO}$ e meio VAZIO. O problema é que normalmente as coisas não são classificadas dessa forma; sempre se tenta classificar as coisas de maneira exata ou abrupta [13], muitas vezes descartando os estados intermediários. Um conhecedor da metodologia proposta por Zadeh analisaria da seguinte forma:

- O recipiente do meio está CHEIO com grau $50 \%$ e VAZIO com grau $50 \%$.

- O recipiente da direita está CHEIO com grau $0 \%$ e VAZIO com grau $100 \%$.

- O recipiente da esquerda está CHEIO com grau $100 \%$ e VAZIO com grau $0 \%$.

Atualmente existem várias ferramentas para fazer inferência nebulosa. Pode-se citar o CLIPS e o NEBULOSO CLIPS [18], que são ferramentas de conversão gratuitas e podem facilmente se integrar a um programa, usando conceito de agentes, inferência abrupta e também linguagem de programação $C$, sendo de grande uso na Europa, bem como nas Forças Armadas Americanas.

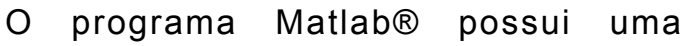
ferramenta para implementação de sistemas de inferência nebulosos, chamada Nebuloso Logic Toolbox. Essa ferramenta possui onze tipos de funções de pertinência já programadas. Como o Matlab® foi utilizado para implementar o sistema proposto por este trabalho, a figura 2, apresentada no final do trabalho, mostra um exemplo de cada função de pertinência existente no programa (Matlab® Toolbox).

No MATLAB tem-se um recurso onde se pode elaborar um sistema de inferência nebuloso. A figura 3, no final do trabalho, mostra a tela que aparece no MATLAB ao se digitar no prompt do
MATLAB a palavra fuzzy que é o editor de sistema de inferência nebulosa.

Considere o caso em que se deseja determinar o consumo esperado de um refrigerante em uma dada região em função da temperatura ambiente e do seu preço unitário. Têm-se duas entradas (temperatura ambiente e preço unitário) e uma saída (consumo esperado). Pode-se usar o seguinte procedimento:

c.1) Nebulização das entradas e definição das saídas.

O modelo tem duas variáveis de entrada que são a temperatura ambiente (entrada 1) e o preço unitário do refrigerante (entrada 2) e uma saída que é o consumo esperado do refrigerante. $\mathrm{Na}$ opção EDIT seleciona-se ADD INPUT conforme ilustrado na figura 4.

Adiciona-se uma variável, pois se tem duas variáveis de entrada. Como a saída é única, não há necessidade de adicionar mais nenhuma (na opção ADD OUTPUT). Aparece a tela da figura 5.

Suponha que a temperatura ambiente (entrada 1) seja classificada por temperaturas BAIXA, MÉDIA e ALTA e modeladas por três funções de pertinência Gaussianas. Dando um duplo clique em INPUT $\mathbf{1}$ aparece a tela que possibilita definir a nebulização da entrada 1 conforme ilustrado na figura 6.

Digita-se em RANGE o domínio da variável temperatura (no caso aqui ilustrado digitou-se o domínio de 15 a 45 graus $C$ ), digita-se o nome da variável em NAME e seleciona-se ADD MFs (figura 7).

Na caixa de diálogos pode-se selecionar o tipo de função de pertinência desejado como também o número de funções de pertinência que serão ajustadas na entrada selecionada (figura 8).

Neste caso, selecionou-se 3 funções de pertinência Gaussianas para representar as temperaturas BAIXA (mf1) com parâmetros 6,37 e 15, MÉDIA (mf2) com parâmetros 6,37 e 30 e ALTA (mf3) com parâmetros 6,37 e 45 (figura 9).

O mesmo procedimento é feito para a segunda entrada; suponha que o preço unitário do refrigerante (entrada 2) seja classificado por preços BAIXO, MÉDIO e ALTO e modelados por três funções de pertinência Gaussianas. Dando um duplo clique em INPUT 2 com domínio de 1 a 6 unidades monetárias, tem-se preço BAIXO representado por $\mathbf{m f 1}$ com parâmetros 1,06, preço MÉDIO representado por $\mathrm{mf2}$ com parâmetros 1,06 e 3,05 e preço ALTO representado por $\mathbf{m f 3}$ com parâmetros 1,06 e 6 (figura 10).

O mesmo procedimento é feito para a saída; suponha que o consumo esperado do refrigerante (saída 1) seja classificado por consumos PEQUENO, MÉDIO e GRANDE e modelados por três funções de pertinência triangulares. Dando um duplo clique em OUTPUT 
1 com domínio de 500 a 6000, tem-se consumo PEQUENO representado por $\mathrm{mf1}$ com parâmetros -2250, 500 e 3250; consumo MÉDIO representado por mf2 com parâmetros 500, 3250 e 6000 e consumo GRANDE representado por mf3 com parâmetros 3250, 6000 e 8750.

c.2) Elaboração das regras nebulosas.

A elaboração das regras nebulosas no MATLAB deve ser precedida da definição dos conectivos dos antecedentes (conectivos "AND" ou "O R"), definição das implicações, cujos operadores podem ser "mínimo" ou "produto", agregação dos conseqüentes, cujos operadores podem ser "máximo" ou "soma limitada" e denebulização (ou não) da saída.

Isto é feito selecionando-se em VIEW:

EDIT FIS PROPERTIES (figura 11).

Neste exemplo aqui apresentado definiu-se um Sistema MAMDAMI com as seguintes características:

- AND method - prod

- Or method - max

- Implication - prod

- Agregation - max

- Defuzification - centroid

Para formular as regras nebulosas seleciona-se em VIEW: EDIT RULES (figura 12).

Aparece uma caixa de diálogos onde se seleciona, para cada entrada a função de pertinência desejada, a saída e o peso de cada regra (figura 13). regras:

Neste exemplo tem-se a seguinte base de

- Regra 1 - Se a temperatura é baixa e o preço é baixo então o consumo é grande;

- Regra 2 - Se a temperatura é baixa e o preço é médio então o consumo é médio;

- Regra 3 - Se a temperatura é baixa e o preço é alto então o consumo é pequeno;

- Regra 4 - Se a temperatura é média e o preço é baixo então o consumo é grande;

- Regra 5 - Se a temperatura é média e o preço é médio então o consumo é médio;

- Regra 6 - Se a temperatura é média e o preço é alto então o consumo é pequeno;

- Regra 7 - Se a temperatura é alta e o preço é baixo então o consumo é grande;

- Regra 8 - Se a temperatura é alta e o preço é médio então o consumo é médio;

- Regra 9 - Se a temperatura é alta e o preço é alto então o consumo é baixo.

(figura 14)
A previsão de consumo pode ser vista em VIEW: VIEW RULES. Para o caso apresentado na figura 15 , tem-se que, para uma temperatura de 30 graus $C$ e o preço do refrigerante de 3,5 unidades monetárias, o consumo esperado é de 3250 unidades.

Normalmente, a lógica nebulosa é empregada na construção de sistemas, chamados Sistemas de Lógica Nebulosa [13] ou Sistemas de Inferência Nebuloso (Matlab $®$ Toolbox). Os sistemas de inferência nebulosos são sistemas fundamentados em regras que utilizam variáveis lingüísticas nebulosas para executar um processo de tomada de decisão [1]. A figura 16 mostra um modelo geral, indicando os cinco blocos principais de um sistema de inferência nebuloso [6].

O Sistema de inferência nebuloso tem como entrada valores precisos, não nebulosos, que são mapeados pelas funções de pertinência estabelecidas na construção do sistema, essa é a etapa de nebulização. Essa etapa fornece parâmetros nebulosos a uma máquina de inferência que processa uma série de regras do tipo SE-ENTÃO, constituída de proposições, envolvendo termos de variáveis lingüísticas. Ao final do processamento das regras, o valor nebuloso, que foi obtido como resposta, é denebulizado se a máquina de inferência tiver como saída valores nebulosos, obtendo-se assim uma saída precisa novamente. Se a máquina de inferência tiver como saída valores precisos, esses já são respostas do sistema [3], [6].

\section{Identificação Nebulosa}

A identificação nebulosa é o estabelecimento de uma estrutura e de parâmetros de um modelo nebuloso, de tal maneira que o modelo tenha um comportamento próximo àquele do processo real [23].

Dessa operação obtém-se um conjunto de regras (implicações nebulosas) e a geração de funções de pertinência. Isso pode ser conseguido através da opinião de especialistas ou, automaticamente, utilizando-se equações relacionais.

Em sistemas baseados em regras, as relações entre as variáveis são representadas através de regras nebulosas do tipo "SE ENTÃO", seguindo a forma geral: SE proposição antecedente ENTÃO proposição conseqüente.

A proposição antecedente é sempre uma proposição nebulosa, do tipo x é $A$, onde $x$ é uma variável lingüística, e $A$ é um termo lingüístico. Para definir o quanto a variável $x$ pertence ao termo lingüístico $A$, utilizaremos um grau de pertinência (entre 0 e 1 ) associado a variável. A proposição conseqüente apresentará formas 
variadas, dependendo do modelo nebuloso que for utilizado.

\section{Saída do Modelo Nebuloso}

A saída (proposição conseqüente) de um modelo nebuloso se realiza através de seis passos [24]:

1. Determinação de um conjunto de regras nebulosas (criação das regras);

2. Nebulização das entradas utilizando as funções de pertinência;

3. Combinação das entradas nebulizadas em cada regra nebulosa para estabelecer a ativação da regra;

4. Cálculo da parte conseqüente da regra;

5. Combinação das partes conseqüentes das regras para obter a distribuição de saída;

6. Denebulização da saída

1 - Criação da regra nebulosa: As regras nebulosas descrevem como o Sistema de Inferência Nebuloso deve realizar a decisão de classificação ou controle. São escritas na seguinte forma: SE (entrada 1) E/OU (entrada 2).ENTÃO (saída).

2 - Nebulização: A etapa de nebulização mapeia a entrada (ou característica) entre valores de 0 a 1 através das funções de pertinência. As funções mais utilizadas são:

* Triangular: é especificada por três parâmetros $\{a, b, c\}$, a qual determina a coordenada $x$ dos três cantos do triângulo (figura 17a).

* Trapezoidal: é especificada por quatro parâmetros $\{a, b, c, d\}$ (figura 17b).

* Gaussiana: é especificada por dois parâmetros $\{s, c\}$ (figura 17c).

Gaussiana $(x ; s, c)=\exp \{-(x-c) / s\} 2$

* Sino: é especificada por três parâmetros $\{a, b, c\}$ (figura $17 d$ ). $\operatorname{Sino}(x ; a, b, c)=1 /(1+[(x-c) / a] 2 b)$

* Sigmoide: é especificada por dois parâmetros $\{a, c\}$ (figura 17e).

$$
\operatorname{Sig}(x ; a, c)=1 /(1+\exp [-a(x-c)])
$$

3 - Combinação das entradas nas regras nebulosas: Nas regras nebulosas são utilizados os conceitos AND e OR e para implementá-los são utilizados as t-norms e as t-conorms, respectivamente.

4 - Parte conseqüente de cada regra: $A$ parte conseqüente de cada regra é conseguida através do uso de algum operador de implicação. Os mais utilizados são a de Mamdami e Larsen.

5 - Combinação de todas as partes conseqüentes: As saídas de todas as regras devem ser combinadas para obter a distribuição de saída nebulosa. Geralmente é utilizado o operador de união.

6 - Denebulização: Em muitos casos é desejável que a saída do sistema não seja nebulosa e sim uma saída definida. A etapa de denebulização mapeia a saída nebulosa em um valor definido. Algumas estratégias de denebulização são:

* Método do máximo critério (MAX): O máximo critério acha o ponto no qual a distribuição de saída possui o seu primeiro valor de máximo (figura 18).

* Método da média dos máximos (MOM): O MOM acha o valor médio onde a saída possui seus máximos valores. Isto pode ser computado como $\mathrm{z}_{\mathrm{o}}=\Sigma(\mathrm{wj} / \mathrm{l})$, onde wj são os valores no qual a função de pertinência possui seu máximos valores e I é o número de valores máximos encontrados (figura 18).

* Método de centro de massa (COA): É largamente usado. Essa estratégia procura pelo centro de gravidade da distribuição de saída "fuzzy" [25] (figura 18).

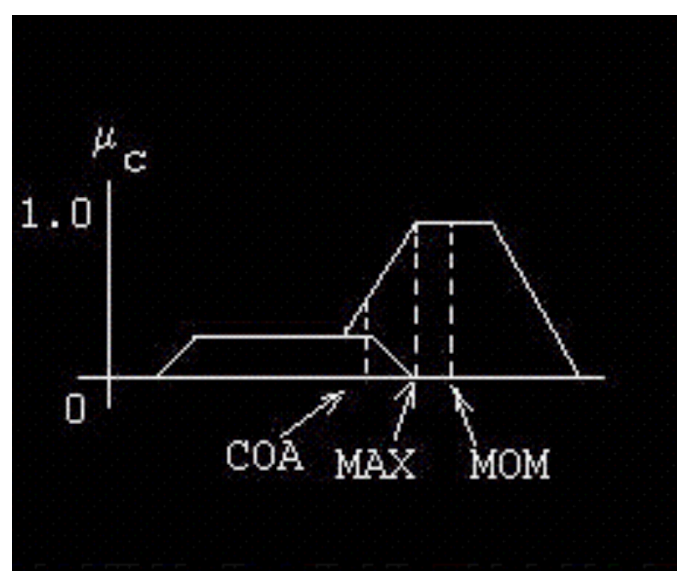

Figura 18 - Estratégias de denebulização

\section{Alguns modelos nebulosos}

Alguns modelos nebulosos são largamente utilizados em várias aplicações. Geralmente as diferenças entre os sistemas estão na sua parte conseqüente, no seu processo de agregação das várias regras e na denebulização do sistema.

Modelo Nebuloso de Mamdami: Neste modelo as implicações nebulosas são modeladas pelo operador de Mamdami (mínimo) e as regras são agregadas através do operador de união (máximo). Assumindo duas regras SE-ENTÃO da seguinte forma:

Regra 1: SE x é A1 e y é B1 ENTÃO $z$ é C1 
Regra 2: SE x é A2 e y é B2 ENTÃO z é C2 Fato: $x$ é xo' e y é yo'

Conseqüência: $z$ é $C$

A ativação de cada regra, denotado por ai, $i=1,2$, são calculadas por:

$\mathrm{a} 1=\mathrm{A} 1(\mathrm{xo}) \wedge \mathrm{B} 1(\mathrm{yo})$ (conectiva AND)

$\mathrm{a} 2=\mathrm{A} 2(\mathrm{xo}) \wedge \mathrm{B} 2(\mathrm{yo})($ conectiva AND)

xo e yo são as entradas xo' e yo'

nebulizadas. A saída de cada regra é dada por: Mamdami)

$\mathrm{C} 1^{\prime}(\mathrm{w})=\mathrm{a} 1 \wedge \mathrm{C} 1(\mathrm{w})$ (operador de Mamdami).

$C 2^{\prime}(w)=a 2 \wedge C 2(w)$ (operador de

A saída geral do sistema é computada pelo operador de união:

$C(w)=C 1^{\prime}(w) \vee C 2^{\prime}(w)=((a 1 \wedge C 1(w)) \vee$ $(\mathrm{a} 2 \wedge \mathrm{C} 2(\mathrm{w}))$.

A figura 19 mostra graficamente este modelo de raciocínio nebuloso.

Modelo Nebuloso de Larsen: É uma variação do modelo de Mamdami freqüentemente encontrado na literatura [27]. Ao invés de utilizarse do operador de Mamdami nas implicações nebulosas das regras, é utilizado o operador de Larsen (produto). Portanto o modelo nebuloso de Mamdami pode ter variações se forem feitas diferentes escolhas para as conectivas AND (tnorms) e OR (t-conorms). A figura 20 mostra o raciocínio nebuloso do modelo de Larsen.

Nesses dois modelos, se for necessária uma saída definida, é utilizada uma etapa de denebulização através dos métodos do 'máximo critério', da 'média máxima' ou 'do centro de massa'.

Modelo de Sugeno: Sugeno e Takagi [26] usaram a seguinte arquitetura:

Regra 1: SE x é A1 e y é B1 ENTÃO z1 = $a 1 x+b 1 y+r 1$

Regra 2: SE x é A2 e y é B2 ENTÃO z2 = $a 2 x+b 2 y+r 2$

Fato: $x$ é xo' e y é yo'

Conseqüência: z é zo

$A$ ativação da regra é dada por: $\mathrm{a} 1=\mathrm{A} 1(\mathrm{xo}) \wedge \mathrm{B} 1(\mathrm{yo}) \mathrm{a} 2=\mathrm{A} 2(\mathrm{xo}) \wedge \mathrm{B} 2(\mathrm{yo})$

A saída de cada regra é conseguida através de uma relação polinomial:

r2

$z 1=a 1 x o+b 1 y o+r 1 z 2=a 2 x o+b 2 y o+$

$\mathrm{Na}$ agregação das regras, feita através do centro de massa, é conseguida uma saída definida (figura 21).
Modelo nebuloso de Tsukamoto: Neste modelo Tsukamoto [29] admite que todas as funções de pertinência são monotônicas. O centro de massa é utilizado para obter a saída, que no caso já é definida. A figura 22 mostra o raciocínio deste modelo.

\section{Raciocínio nebuloso}

Raciocínio nebuloso é um procedimento de inferência usado para obter conclusão de um conjunto de regras IF-THEN de uma ou mais condições. Há duas importantes regras de inferência nebulosas denominadas modus ponens generalizada (GMP) e modus tollens generalizada (GMT) [25], dada por:

Fato: $x$ é $A^{\prime}$

Regra: SE x é A ENTÃO y é B (GMP)

Conseqüência: y é B'

Fato: y é B'

Regra: SE x é A ENTÃO y é B (GMT)

Conseqüência: $x$ é $A^{\prime}$

A implicação nebulosa é baseada na regra composicional. O GMP se reduz ao modus ponens clássico quando $A^{\prime}=A$ e $B^{\prime}=B$, e está intimamente relacionado à inferência dirigida $\mathrm{a}$ dados, a qual é útil em lógica nebulosa de controle [25].

O GMT se reduz ao modus tollens clássico quando $B^{\prime}=$ não $B$ e $A^{\prime}=$ não $A$, e está intimamente ligado à inferência dirigida a objetivos, o que é comumente usado em sistemas especialistas, especialmente na esfera de diagnósticos médicos [25].

As regras nebulosas podem ser classificadas em três tipos dependendo de sua forma conseqüente [29].

Tipo 1: regras nebulosas com a parte conseqüente constante:

\section{$\mathrm{R}$ : SE x1 é $A 1$ e ... xm é $A m$ \\ ENTÃO y é C1}

Tipo 2: regras nebulosas com a parte conseqüente sendo uma combinação linear:

R: SE x1 é $A 1$ e .... e xm é Am

ENTÃO y é $g(x 1, \ldots, x m)=b o+b 1 \times 1$ $+\ldots+$ bmxm

Tipo 3: regras nebulosas com a parte conseqüente sendo um conjunto nebuloso:
$\mathrm{R}$ : SE x1 é $A 1$ e ... e xm é $A m$
ENTÃO y é $B$

Nas regras acima, xi e y denotam variáveis de entrada e saída respectivamente. Os termos lingüísticos são conjuntos nebulosos parametrizados, no qual a forma é determinada 
por poucos parâmetros (conjunto nebuloso triangular, trapezoidal, sigmoidal, entre outros). $\mathrm{O}$ termo c1 denota um valor constante, e $\mathrm{g}(\mathrm{x} 1+\ldots+$ $\mathrm{xm})=\mathrm{bo}+\mathrm{b} 1 \mathrm{x} 1+\ldots+$ bmxm é uma combinação linear das variáveis de entrada onde bi's são coeficientes constantes. Por fim, B indica um conjunto nebuloso parametrizado ou não parametrizado. Conjuntos nebulosos não parametrizados são definidos pela representação de seus valores e seu grau de pertinência. Como exemplo, temos: $(120,0.1)\}$ velocidade baixa $=\{(0,1.0),(80,0.5)$,

Podemos ter regras simples com antecedentes simples:

Fato: $x$ é A'

Regra: SE x é A ENTÃO z é C

Conseqüência: z é C'

Ou podemos ter múltiplas regras com múltiplos antecedentes:

Fato: x é A' e y é B'

Regra 1: SE x é A1 e y é B1 ENTÃO z é C1

Regra 2: SE x é A2 e y é B2 ENTÃO z é C2

Conseqüência: z é C'

Nas conexões AND (e) são utilizadas as normas triangulares e para realizar as ligações entre as diversas regras são utilizados as conormas triangulares.

Ainda podem-se classificar as regras nebulosas quanto ao número de suas entradas e saídas. Nesse caso o sistema será referenciado como MIMO (múltiplas entradas e múltiplas saídas) e MISO (múltiplas entradas e saída simples) [25].

Cabe aqui ressaltar que, neste trabalho, foram utilizadas as palavras Nebulização e Denebulização em substituição às palavras fuzzification e defuzzification, empregadas por diversos autores [16], e em substituição às palavras fuzzificação e defuzzificação [13], utilizadas por alguns autores brasileiros. As palavras serão assim utilizadas para que não haja qualquer dúvida, já que neste trabalho foi adotada a nomenclatura Lógica Nebulosa ao invés de Lógica Nebulosa.

A base de regras é a parte do sistema que contém o conjunto de regras ou proposições, todas nebulosas. As variáveis antecedentes ou conseqüentes são variáveis do tipo lingüísticas e os valores possíveis dessas variáveis são representados por conjuntos nebulosos [13]. As regras ou proposições devem estar no formato SE - ENTÃO, correlacionando as variáveis, antecedentes e conseqüentes, como mostrado abaixo.

\section{Metodologia}

Esse tipo de problema já foi tratado por outros métodos, inclusive o Data Mining [14].

A originalidade deste trabalho está em abordar o problema usando um software de inferência nebulosa.

A fim de representar conhecimentos de maneira precisa, agentes de software costumam utilizar linguagens de representação de conhecimento baseados em lógica. Diferentes tipos de lógica podem ser utilizados como lógica proposicional, lógica de primeira ordem ou ainda a lógica nebulosa.

Inicialmente, os sistemas especialistas eram criados do nada. Mas devido ao fato de os sistemas serem construídos como um conjunto de representações declarativas (em sua maioria, regras) combinadas com um interpretador dessas representações, era possível separar o interpretador do conhecimento específico do domínio da aplicação e assim criar um sistema que podia ser usado para elaborar novos sistemas especialistas através da adição de novos conhecimentos, correspondentes ao novo domínio do problema. Estes interpretadores resultantes são chamados de "SHELLS", que servem de base para muitos dos sistemas especialistas que estão sendo desenvolvidos. $O$ nome shells vem do fato de tornar transparente as dificuldades inerentes à implementação de uma aplicação em Inteligência Artificial: escolha da representação de conhecimento, do método de busca, ferramentas para encontrar erros, etc.

A construção de sistemas especialistas envolve investimentos em profissionais de diversas áreas, implicando em riscos maiores para a produção. Uma solução para este problema é o uso de ferramentas capazes de prototipar, avaliar e implementar o projeto de um sistema, os chamados "SHELLS". Procura-se, assim, diminuir a necessidade de recursos necessários, entre eles o tempo envolvido e tenta-se conciliar a alta produtividade e a versatilidade de ferramentas qualificadas.

Um shell é uma ferramenta genérica para implementação de bases de conhecimento. Que de tal modo, o desenvolvedor não se preocupa com a máquina de inferência, apenas com o conjunto de regras que modelam o conhecimento desejado.

Normalmente um SHELL inclui:

- Ferramentas para introduzir conhecimento;

- Um ou vários motores de Inferência;

- Mecanismos para tratar imprecisão;

- Mecanismos para tratar incertezas;

- Mecanismos de seguir passo a passo o funcionamento do programa de modo a encontrar possíveis erros; 
- Uma comunicação homem-máquina.

Exemplos de SHELLS para a construção de sistemas especialistas:

- Expert Sinta: sua finalidade é embutir dentro de seus próprios ambientes, meios para construção de interfaces gráficas com o usuário final, além de mecanismos de troca de dados com outras aplicações;

- KappaPC: permite escrever aplicações em um ambiente gráfico e gerar códigos padrão ANSI C. Ele é uma ferramenta de auxílio na construção de sistemas baseados em conhecimento, usando frames, regras de produção, e programação orientada a objetos;

- VP-Expert: sistema baseado em regras. Usa o raciocínio para frente e possui mecanismos embutidos para o tratamento de imprecisão com o paradigma dos fatores de confiança;

- Advisor: ambiente de desenvolvimento baseado na tecnologia de regras de negócio, construído 100\% Java;

- Expert: conhecido também como Nexpert, é uma ferramenta de desenvolvimento para ambientes Windows e Unix, que fornece a gerentes e desenvolvedores a capacidade de integrar a experiência do negócio;

- Clips: é a abreviação de 'C Language Integrated Production System', foi projetado pela NASA/Johnson Space Center;

- FuzzyClips: utiliza-se da teoria e dos cálculos da Lógica Fuzzy, para representar o conhecimento.

\section{Algumas aplicações}

- Sistema especialista para primeiros socorros para cães - É um sistema especialista que usa o expert Sinta e utiliza o conhecimento humano para auxílio no diagnóstico veterinário [30].

- Aplicações Industriais de Matemática Nebulosa:

- NISSAN: freios antiderrapantes

- GM: sistema de transmissão nebuloso

- SANYO: microondas

- SHARP: refrigeração

- BOSCH: máquinas de lavar

- HITACHI: aspirador

- PANASONIC: camcorder

\section{- Aplicações Comerciais da Matemática Nebulosa:}

- Yamaichi Securities: Sistema de Gerenciamento de Fundos de Investimento;

- Fuji Bank: Sistema de Negociação de Bolsa de Valores;

- World Bank: Sistema de Investimento;

- Metus Systems: Sistema nebuloso de detecção de fraude no sistema de saúde.

Neste trabalho, toda a informação utilizada na criação das funções de pertinência e das regras foi extraída de um banco de dados de uma grande empresa brasileira especializada em crédito pessoal. A amostra do banco de dados utilizada contém todos os clientes da empresa, ou seja, pessoas que conseguiram algum empréstimo, no período de novembro de 2001 a outubro de 2002. Extraindo o conhecimento desta forma, qualquer alteração de comportamento dos clientes da empresa deverá ser refletida pelo banco de dados imediatamente, assim é possível sempre fazer essa análise com uma amostra atualizada do banco de dados, e conseguir que o sistema responda sempre de modo a mostrar o que está ocorrendo com os clientes da empresa naquele momento.

Primeiramente, foi extraída uma amostra do banco de dados da empresa. $\mathrm{Na}$ retirada desta, não foi utilizado um filtro, ou seja, todos os clientes da empresa, no período estudado, estão na amostra com todas as informações disponíveis.

Após a retirada da amostra, os dados de todos os clientes foram carregados em uma planilha Excel囚. O próximo passo foi, então, analisar as informações disponíveis e retirar aquelas que não seriam utilizadas no decorrer do trabalho. Para isso, foram criados filtros nas colunas a fim de que os registros incompletos ou as informações digitadas incorretamente fossem retirados. Desta forma restaram ainda, aproximadamente 35.500 perfis de clientes.

As informações utilizadas neste trabalho foram: Estado Civil (casado, solteiro, divorciado e viúvo), Tipo de Profissão (assalariado, autônomo, funcionário público e aposentado), Renda em Reais (menos de $\mathrm{R} \$ 500,00$, entre $\mathrm{R} \$ 500,00$ e $R \$ 800,00$, entre $R \$ 800,00$ e $R \$ 1.100,00$, entre $R \$ 1.100,00$ e $R \$ 1.400,00$ e mais de $R \$$ $1.400,00$ ), Idade (menos de 30 anos, entre 30 e 40 , entre 40 e 50 , entre 50 e 60 e mais de 60 anos) e Porcentagem que a prestação do empréstimo compromete da renda do cliente (menos de $10 \%$, entre 10 e 15 , entre 15 e 20 , entre 20 e 25 e mais de $25 \%$ ).

A situação do cliente pode ser Adimplente ou Inadimplente.

Após a mineração de dados, foi criada uma outra planilha onde foram elaboradas fórmulas simples para verificar a quantidade de cada um 
dos itens escolhidos na planilha inicial que continha o banco de dados. Após toda essa contagem, foi utilizada a teoria de probabilidade para encontrar os valores de todos os itens relacionados com a Situação do cliente, como por exemplo, a quantidade de cientes Adimplentes e Inadimplentes por Estado Civil, Tipo de Profissão ou Faixa Etária. Nesse caso, foi utilizada a noção de probabilidade da interseção entre dois eventos mutuamente exclusivos, por exemplo, quantos clientes são Assalariados e Adimplentes. O resultado é mostrado na tabela 1 .

A criação das funções de pertinência foi baseada nas informações retiradas do banco de dados, mostradas na tabela 1. Essas funções descreverão todos os valores dos graus de pertinência dos elementos do universo em discussão, em relação a um dado subconjunto nebuloso. A escolha da função de pertinência deve ser feita analisando todo o problema, pois qualquer que seja a função escolhida, o mais importante é que ela retrate com máxima fidelidade $o$ conceito apresentado e o comportamento dos elementos do universo em estudo [13].

O primeiro passo foi a criação das funções de pertinência. Todas as funções de pertinência são mostradas nas figuras 23 a 27, apresentadas no final do trabalho.

Após a criação das funções de pertinência para as variáveis de entrada, foi criada a função de pertinência para a variável de saída Situação, com mostrado na figura 28.

No caso da variável de saída, foram criadas as funções de pertinência apenas para o sistema de inferência que utiliza o Modelo Mandani em sua máquina de inferência, pois quando é utilizado na máquina de inferência o modelo Sugeno, as saídas são do tipo linear ou constantes. Neste trabalho, foram utilizadas saídas do tipo constante com o valor correspondente à porcentagem de cada situação, ou seja, Inadimplentes 0.28 e Adimplentes 0.72 .

Após a criação das funções de pertinência, todas as regras foram inseridas no sistema. A última etapa da implementação foi a configuração do sistema, o modelo utilizado para denebulização foi o centroid e os demais parâmetro utilizados não foram alterados, permanecendo a configuração padrão do sistema.

\section{Testes e Resultados}

O passo seguinte à implementação do sistema foi seu teste, o qual foi realizado utilizando os dados do mesmo banco de dados usado na criação do sistema. Foram escolhidos aleatoriamente os perfis de 100 clientes adimplentes e 100 inadimplentes. Esses perfis foram inseridos no sistema produzindo uma resposta, que foi comparada com a situação do cliente descrita no banco de dados.

Os resultados obtidos com a utilização do sistema concordaram com o que está descrito no banco de dados em aproximadamente $80 \%$ das vezes, tanto utilizando o sistema de inferência com o modelo Mandani quanto com o modelo Sugeno. Esse resultado foi obtido analisando todos os dados como um conjunto único de teste e não escolhendo o melhor resultado entre as amostras de clientes adimplentes e inadimplentes.

Os resultados obtidos foram comparados com o nível de inadimplência da empresa, pois, este nível, mostra o quanto eficiente é o resultado da análise que a empresa faz quando concede o empréstimo aos seus clientes. Assim, pode-se dizer que o sistema obtém resultados um pouco mais satisfatórios do que a análise realizada pela empresa, pois esta possui um procedimento para análise do cliente em potencial e tenta emitir um parecer sobre este, se o parecer não é favorável, de acordo com a política da empresa, o crédito não é concedido. Então, pode-se afirmar que o procedimento conseguiu emitir um parecer correto em aproximadamente $72 \%$ das vezes, pois $28 \%$ dos clientes da empresa tornaram-se inadimplentes.

\section{Referências}

1. WAGNER, Adiléa (2003) Extração de Conhecimento a Partir de Redes Neurais Aplicada ao Problema de Cinemática Inversa na Robótica. Rio Grande do Sul. Dissertação (Mestrado em Computação Aplicada) UNISINOS.

2. ÁlVAREZ, Carlos J. V., CANTOR, Diego A. R. (2001) Automatización de una Lavadora Industrial de Ropa Utilizando Técnicas de Control Lógico Secuencial y Lógica Difusa. Bogotá. Monografia (Graduação em Engenharia Eletrônica). Pontifica Universidad Javeriana.

3. BERNARDO FILHO, O., NASCIMENTO, Carlos Augusto S. A. do, RIBEIRO, João A. (1999) Sistema de Informação Geográfica para Auxiliar a Implantação e Avaliação de Provedores de Internet ( $S / G A / A P I)$. Rio de Janeiro. Departamento de Engenharia de Sistemas e Computação. FEN/UERJ.

4. BRAGA, M. J. F., BARRETO, J. M., MACHADO, M. A. S. (1995) Conceitos de Matemática Nebulosa na Análise de Risco. Rio de Janeiro. Editora Arte \& Rabiskus.

5. BUSSAB, W. O. (1990) Análise de Variância e Regressão. $2^{a}$ ed. São Paulo. Editora Atual. 
6. Costa, Alex da, RODRIGUES, Antonio G., SIMAS, Etiene P. L. et al. (2003) Lógica Nebuloso: Conceitos e Aplicações. Rio Grande do Sul. Centro de Ciências Exatas e Tecnológicas, UNISINOS.

7. DAVID JÚNIOR, Jorge, CORRAR, Juiz J. (2002) Mensuração do Risco de Mercado Utilizando Lógica Nebulosa. São Paulo. Departamento de economia. FEA/USP.

8. LÓPEZ, Ihosvany A., SANTIAGO, Orestes L., GALDEANO, José L. V. (2002) Una Aplicación de control difuso para secado de tabaco en hojas. Granada. Departamento de ciências da computação e inteligência artificial. Universidad de Granada.

9. MUKAIDONO, Masao (2001) Nebuloso Logic for Beginners. Singapura. Editora World Scientific.

10. MUKAIDONO, Masao, INTAN, Rolly (2002) "On Knowledge-based Nebuloso Sets". In: International Journal of Nebuloso Systems. Vol. 4, No 2. Junho

11. MENDENHALL, W., SINCICH, T. A Second Course in Statistics: Regression Analysis. 15 ${ }^{\mathrm{a}} \mathrm{Ed}$. Nova Jérsei: Editora Prentice-Hall.

12. MURTEIRA, B. J. F. Probabilidade e Estatística. 2a Ed. Vol. 1. Lisboa. Editora McGraw Hill.

13. OLIVEIRA JÚNIOR, Hime A. (1999) Lógica Difusa: Aspectos Práticos e Aplicações. Rio de Janeiro. Editora Interciência.

14. BARRETO, Jorge Muniz. (2001) Inteligência artificial no limiar do século $X X I$. 3a ed. Florianópolis: Rô Rô Rô Editora, v. 1. 392 p.

15. RAGSDALE, Cliff T. Spreadsheet Modeling and Decision Analysis, A Practical Introduction to Management Science. $3^{\mathrm{a}}$ Ed. Ohio. South-Western College Publishing.

16. WEBER, Rosina de O. (1999) Sistema Especialista Difuso para Análise de Crédito. Santa Catarina. Dissertação (Mestrado em Engenharia de produção). UFSC.

17. YAGER, Ronald R., FILEV, Dimitar P. (1994) Essentials of Fuzzy Modeling and Control. Nova Iorque. John Wiley \& Sons Editores.

18. FRIEDERICH, S., GARDANO, M. (1989) Exerpert Systems Design and Development. Nova Iorque. John Wiley \& Sons Editores.

19. KAUFMANN A., Introduction à la théorie des sous-ensembles flous, Masson, Paris, 1973

20. LOPEZ, Jesus Alfonso, AGUDELO, Oscar Maurício, ALMARIO, Diego
Fernando. (19 de agosto de 2000). [Lógica Difusa]. Disponível: http://tesla.cuao.edu.co/proyectos/ic/nebul osointro.html. Data de acesso 10/08/2003

21. ANDRADE, Marco Túlio C. de. [PCS5711 Computação Difusa]. São Paulo: Departamento de engenharia de computação e sistemas digitais. USP. Março de 2003.

22. 5711-cap2-historico-periodicosassociacoes-2002ciclo1.pdf. Disponível: http://www.pcs.usp.br/ pcs5711/

23. SHAW, I. S., SIMÕES, M. G. (1999). Controle e Modelagem Fuzzy. FAPESP, Editora Edgard Blücher LTDA.

24. SUDKAMP, T., HAMMELL II, R. J. (1996). Rule base completion in fuzzy models, in Fuzzy Modeling: Paradigms and Practices, edited by W. Pedrycz, Kluwer Academic Press, pp. 313-330.

25. LEE, S. J., PLAISTED, D. A. (1990). New applications of a fast propositional calculus decision procedure. Proc. 8th Biennial Conf. of the Canadian Society for Computational Studies of Intelligence (CSCSI-90, Univ. of Ottawa, Ottawa, Canada, 22-25 May 1990), published by CSCSI, pp. 204-211.

26. TAKAGI, T., SUGENO, M. (1985). Fuzzy identification of systems and its applications to modeling and control, IEEE Trans. on Systems, Man and Cybernetics, 15, 116-132.

27. LARSEN, H. L.., YAGER, R. R. (1993). The use of fuzzy relational thesauri for classificatory problem solving in information restrieval and exprert systems. IEEE Trans. in System, Man, and Cybernetics, 23 (1):31-41.

28. TSUKAMOTO, Y. (1979). An Approach to Fuzzy Reasoning Method, Gupta M.M. et al, Advances in Fuzzy Set Theory and Applications, pp. 137-149.

29. LEE, K. M., KWAK, D. H., LEE-KWANG, H. (1996). Fuzzy inference neural network for fuzzy model tuning, IEEE Transactions Systems Man Cybernetics, vol. 26, no. 4B, pp. 637-645.

30. SAVARIS, S. V. A. M. (2002). Sistema especialista para primeiros socorros para cães. Dissertação Submetida à Universidade Federal de Santa Catarina como parte dos requisitos para a obtenção do grau de Mestre em Ciência da Computação. Programa de Pósgraduação em Ciência da Computação. Professor Jorge Muniz Barreto, D.Sc.A. Florianópolis. 
Figuras Anexas

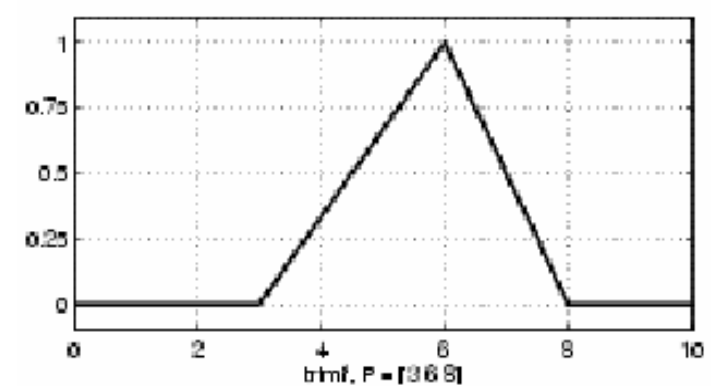

trimf

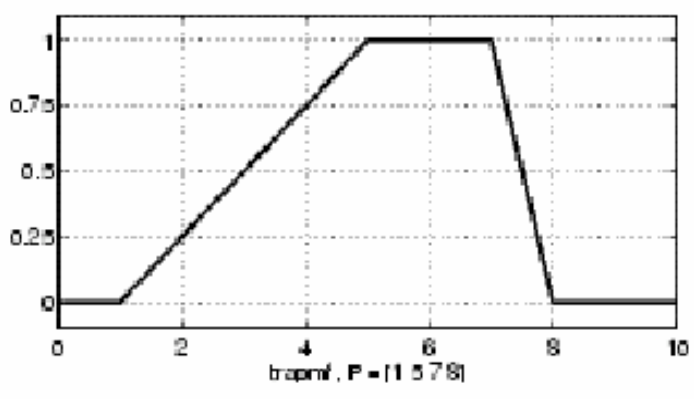

trapmf

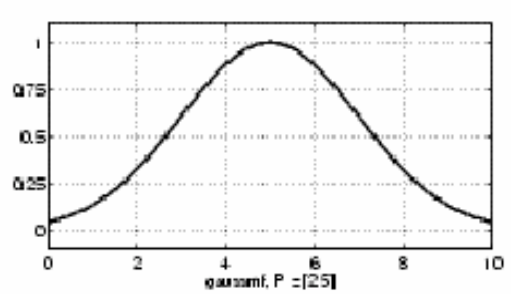

gaussmf

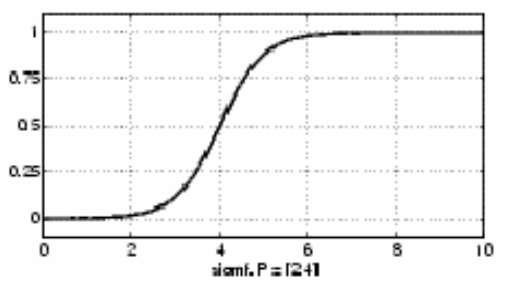

sigmf

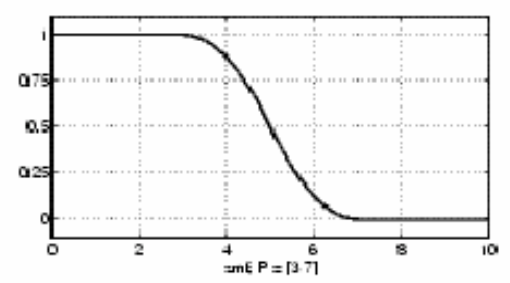

zmf

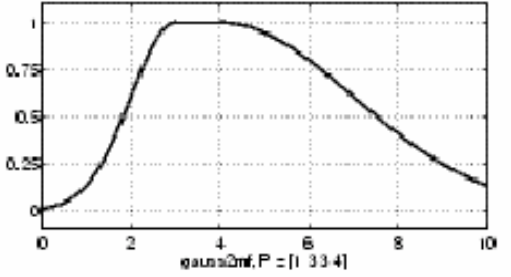

gauss2mf

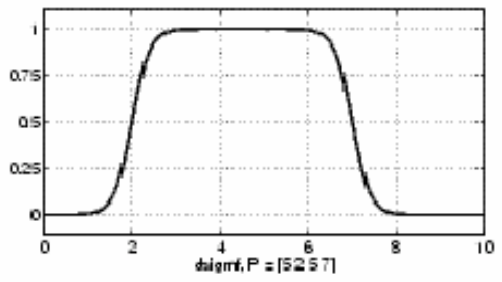

dsigmf

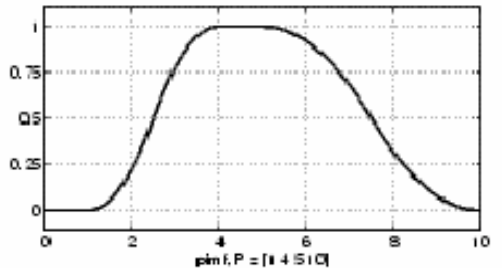

pimf

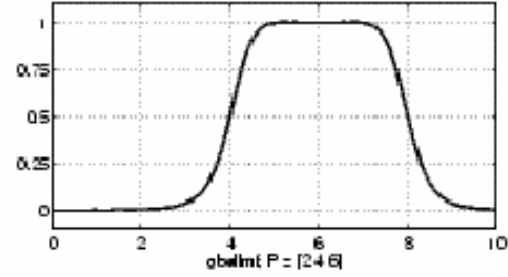

gbellmf

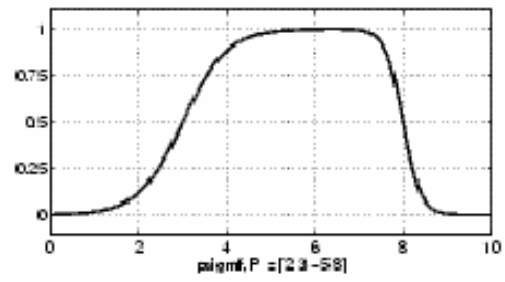

psigmf

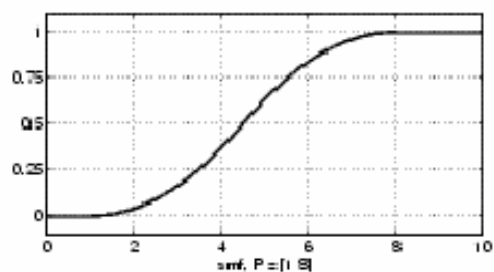

$\mathrm{smf}$

Figura 2 - Funções de pertinência existentes no Matlab ${ }^{\circledR}$ 


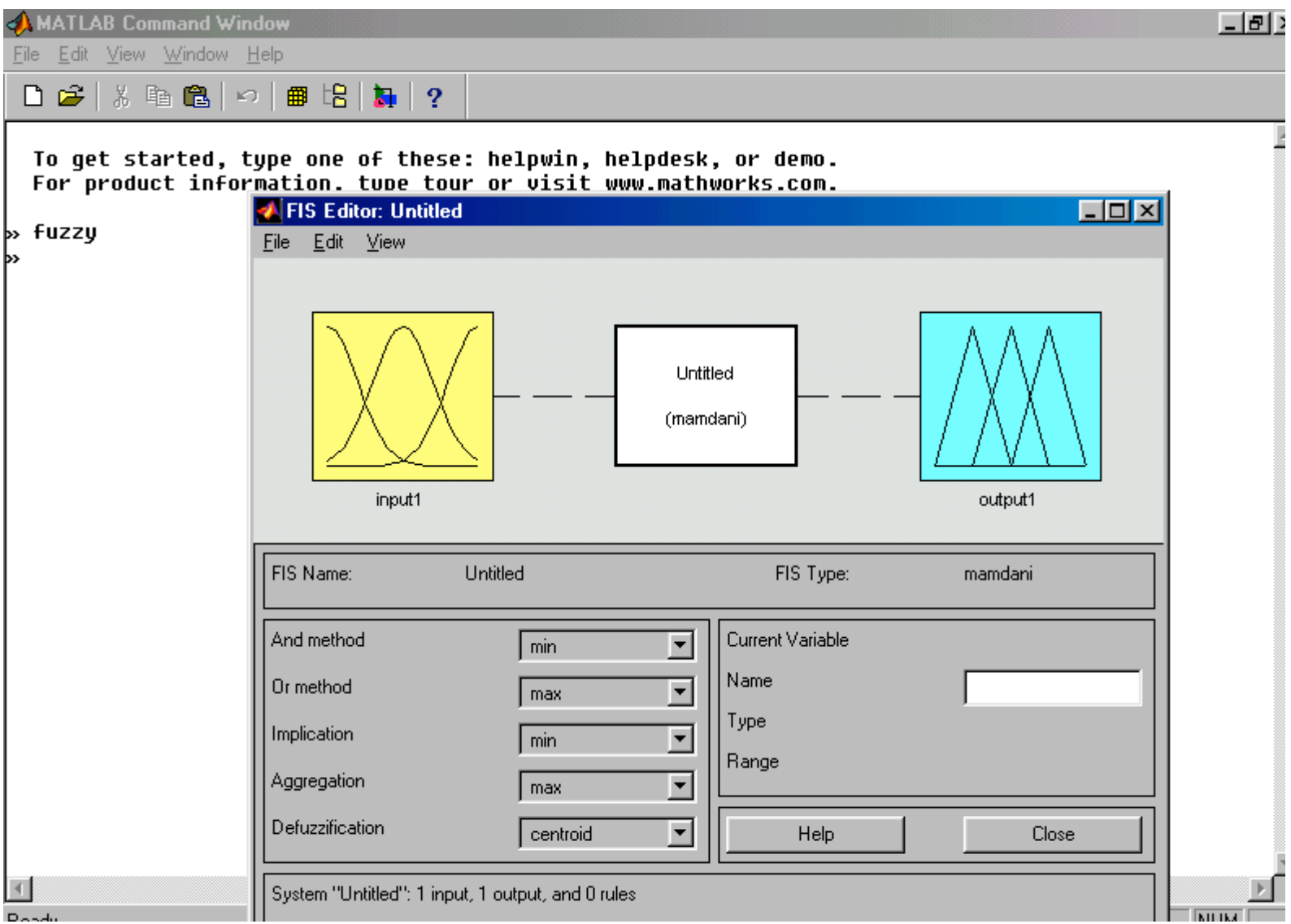

Figura 3 - Tela inicial do sistema de inferência nebulosa no MATLAB

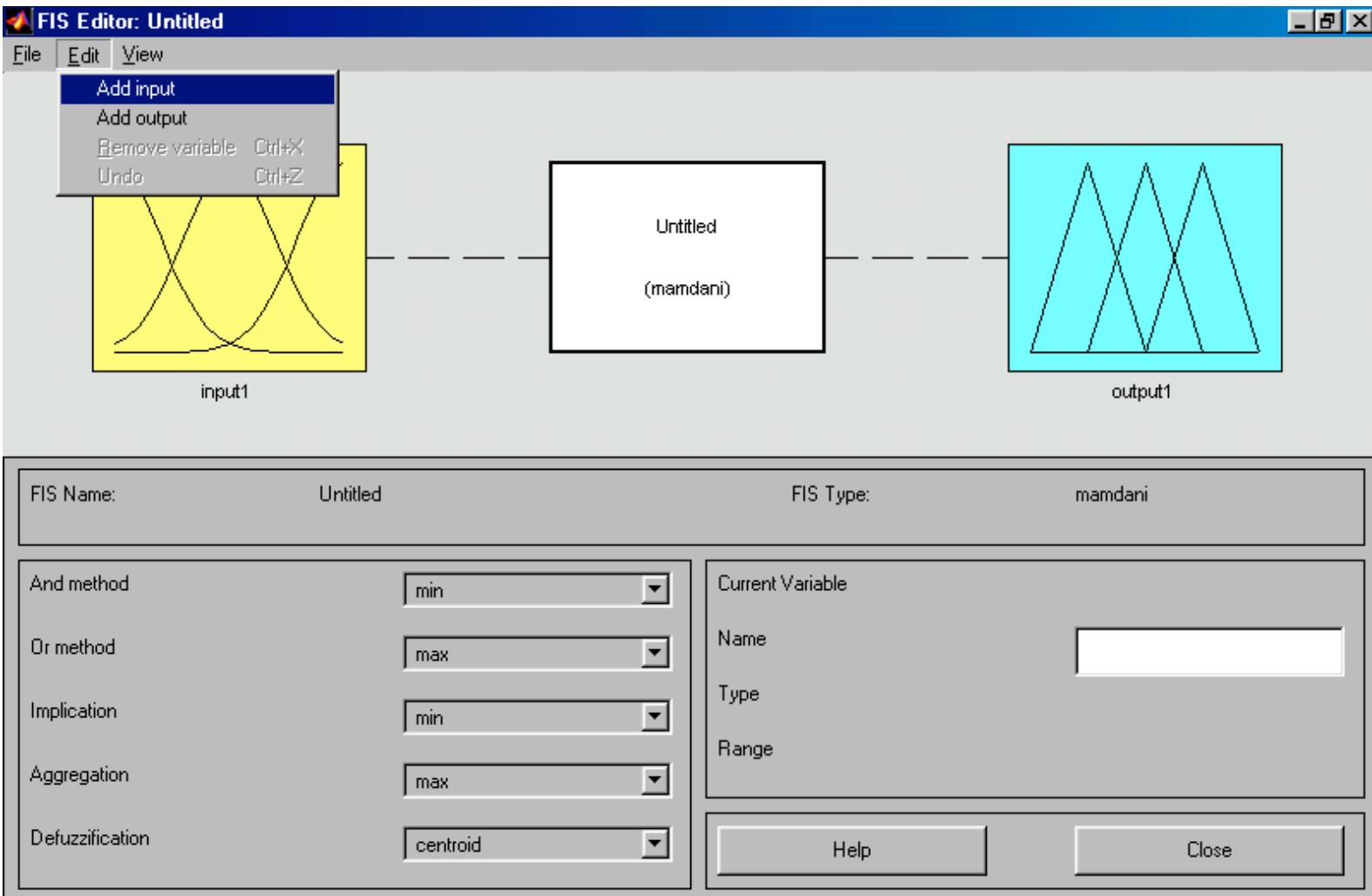

System 'Untitled": 1 input, 1 output, and 0 rules

Figura 4 - Entradas do sistema nebuloso de Mamdami 
AFIS Editor: Untitled

File Edit View

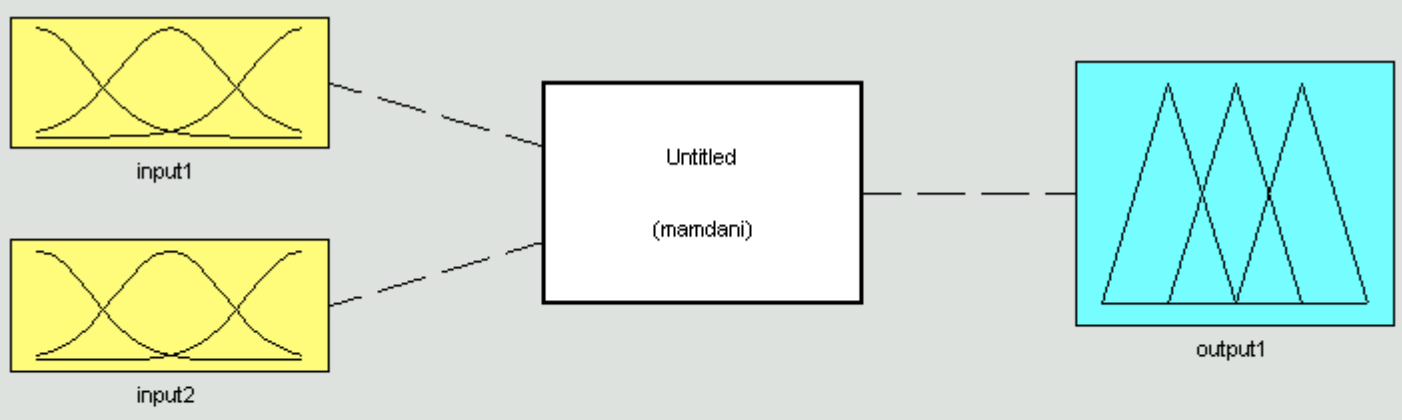

\begin{tabular}{|c|c|c|c|c|}
\hline FIS Name: & Untitled & & FIS Type: & mamdani \\
\hline And method & $\min$ & $\nabla$ & \multirow{4}{*}{$\begin{array}{l}\text { Current Variable } \\
\text { Name } \\
\text { Type } \\
\text { Range }\end{array}$} & \\
\hline Or method & $\max$ & $\nabla$ & & \\
\hline \multirow[t]{2}{*}{ Implication } & $\min$ & $\nabla$ & & \\
\hline & & $\nabla$ & & \\
\hline Defuzzification & centroid & $\nabla$ & Help & Close \\
\hline Ready & & & & \\
\hline
\end{tabular}

Figura 5 - Definição das funções de pertinência das entradas do sistema nebuloso Mamdami

A FIS Editor: Untitled

File Édit View
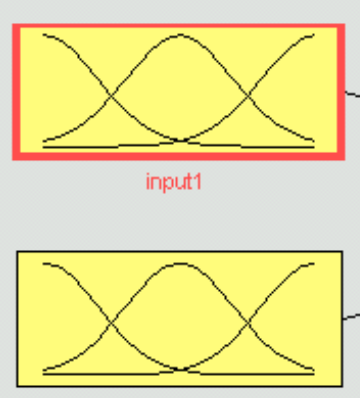

input2

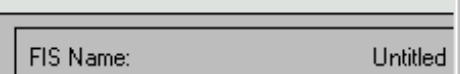

And method

Or method

Implication

Aggregation

Defuzzification

\section{A Membership Function Editor: Untitled}

File Edit View

FIS Variables

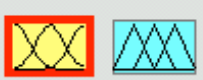

input1 output

$X X$

input2

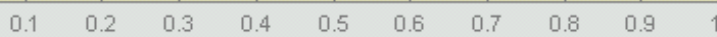

input variable "input1"

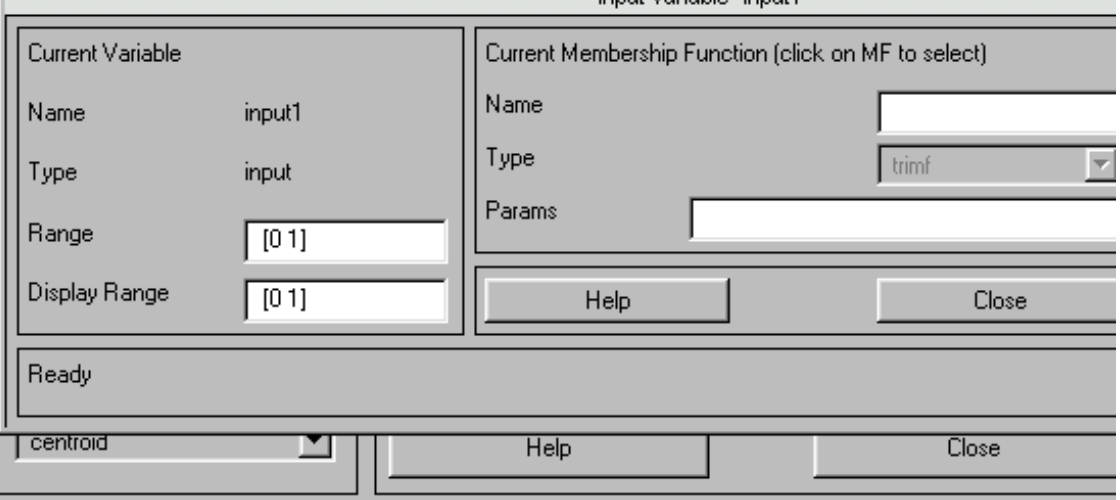

Opening Membership Function Edito

Figura 6 - Definição do domínio das entradas do sistema fuzzy Mamdami 


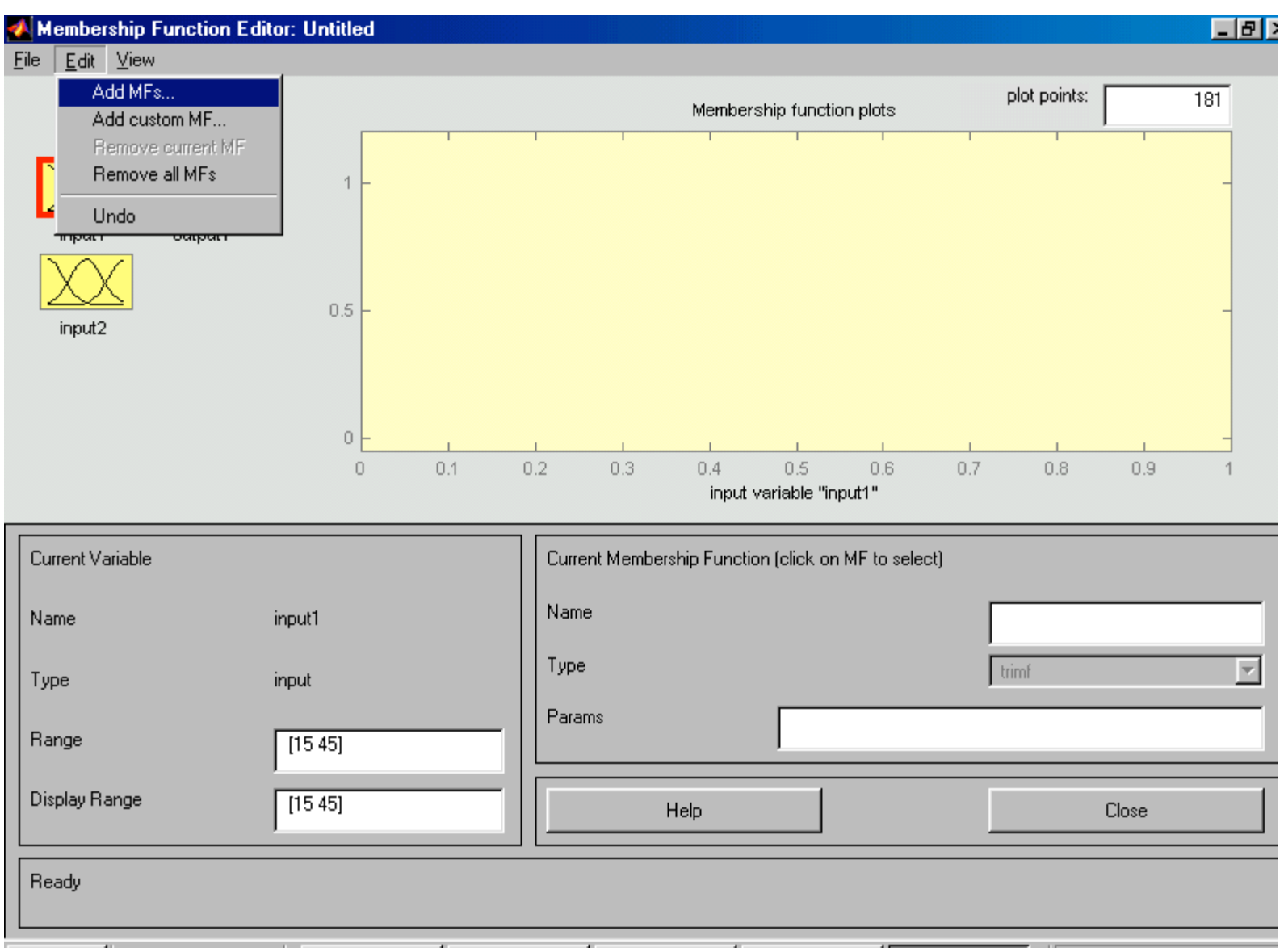

Figura 7 - Entrada das funções de pertinência de Mamdami

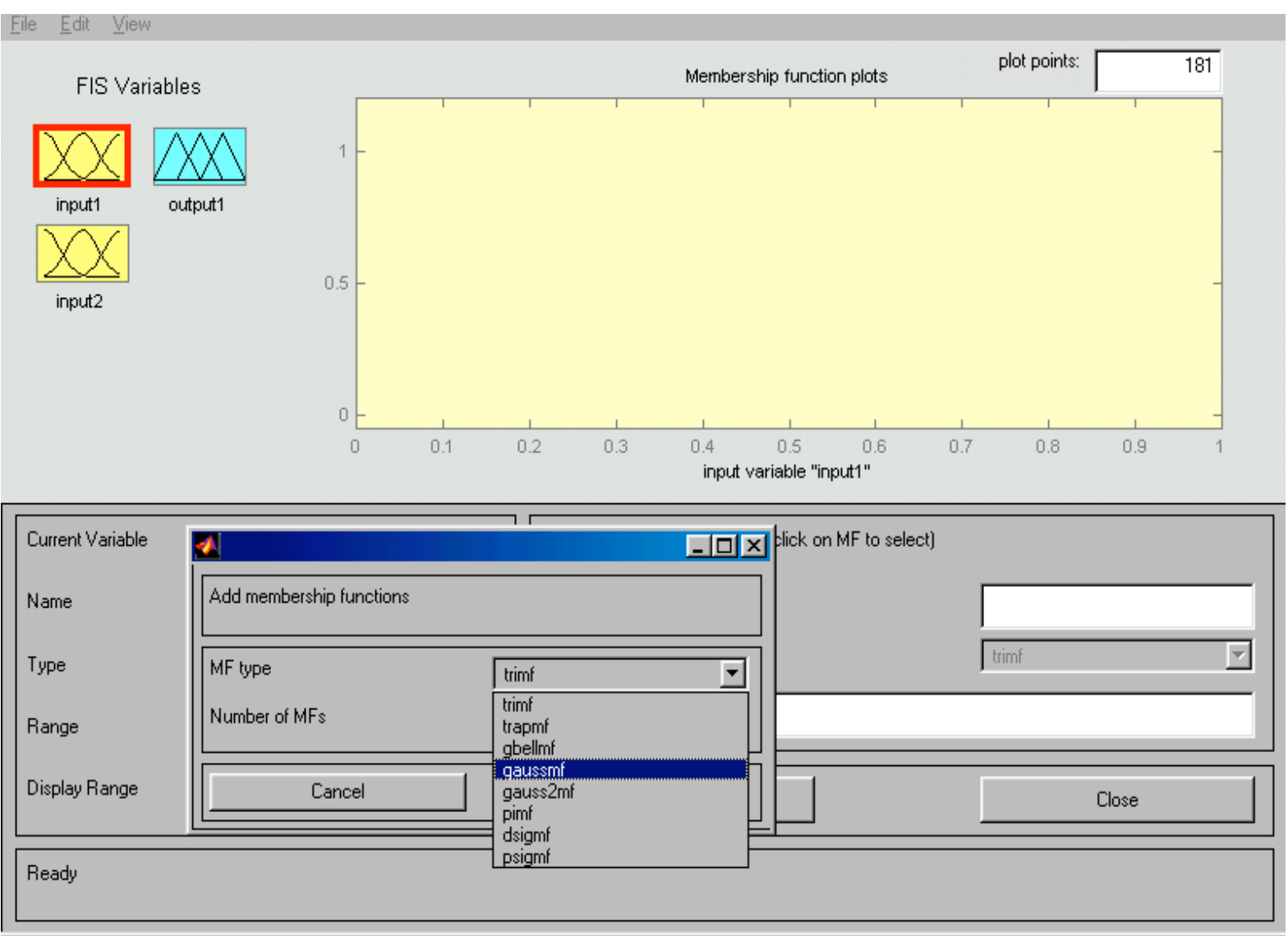

Figura 8 - Definição das funções de pertinência do sistema nebuloso de Mamdami 
A Membership Function Editor: Untitled

File É dit View

FIS Variables
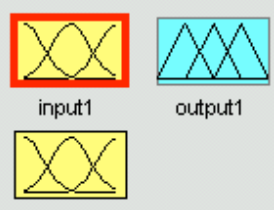

input2

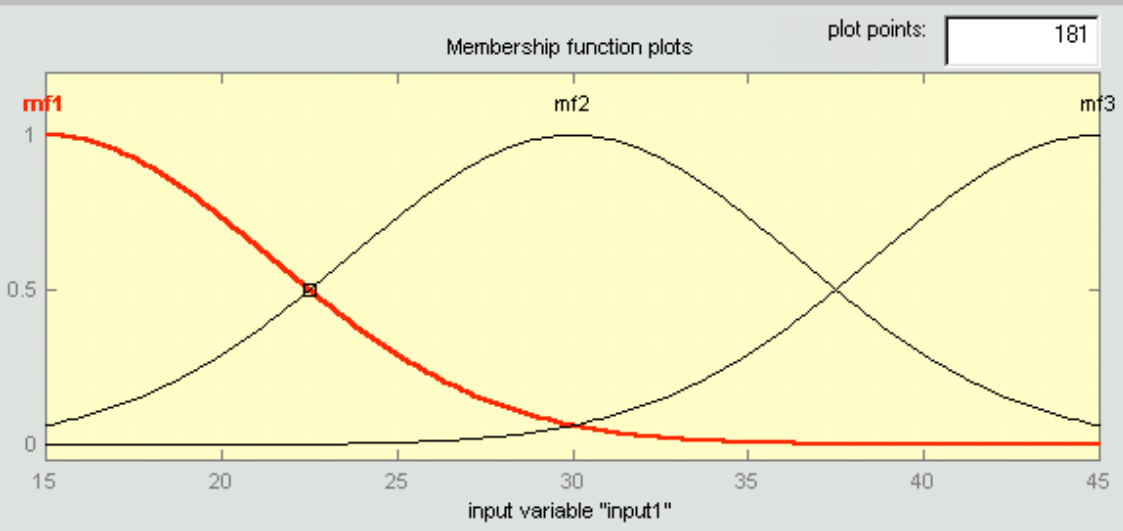

\begin{tabular}{|c|c|c|c|c|c|}
\hline Current Variable & & Current Membership & click on MF to select] & & \\
\hline Name & input1 & Name & & $m f 1$ & \\
\hline Type & input & Type & & gaussmf & $\nabla$ \\
\hline Range & [15 45] & Params & [6.37 15] & & \\
\hline Display Range & [15 45] & Help & & Close & \\
\hline
\end{tabular}

Selected variable "input1"

Figura 9 - Pelo final da entrada 1 do sistema nebuloso de Mamdami

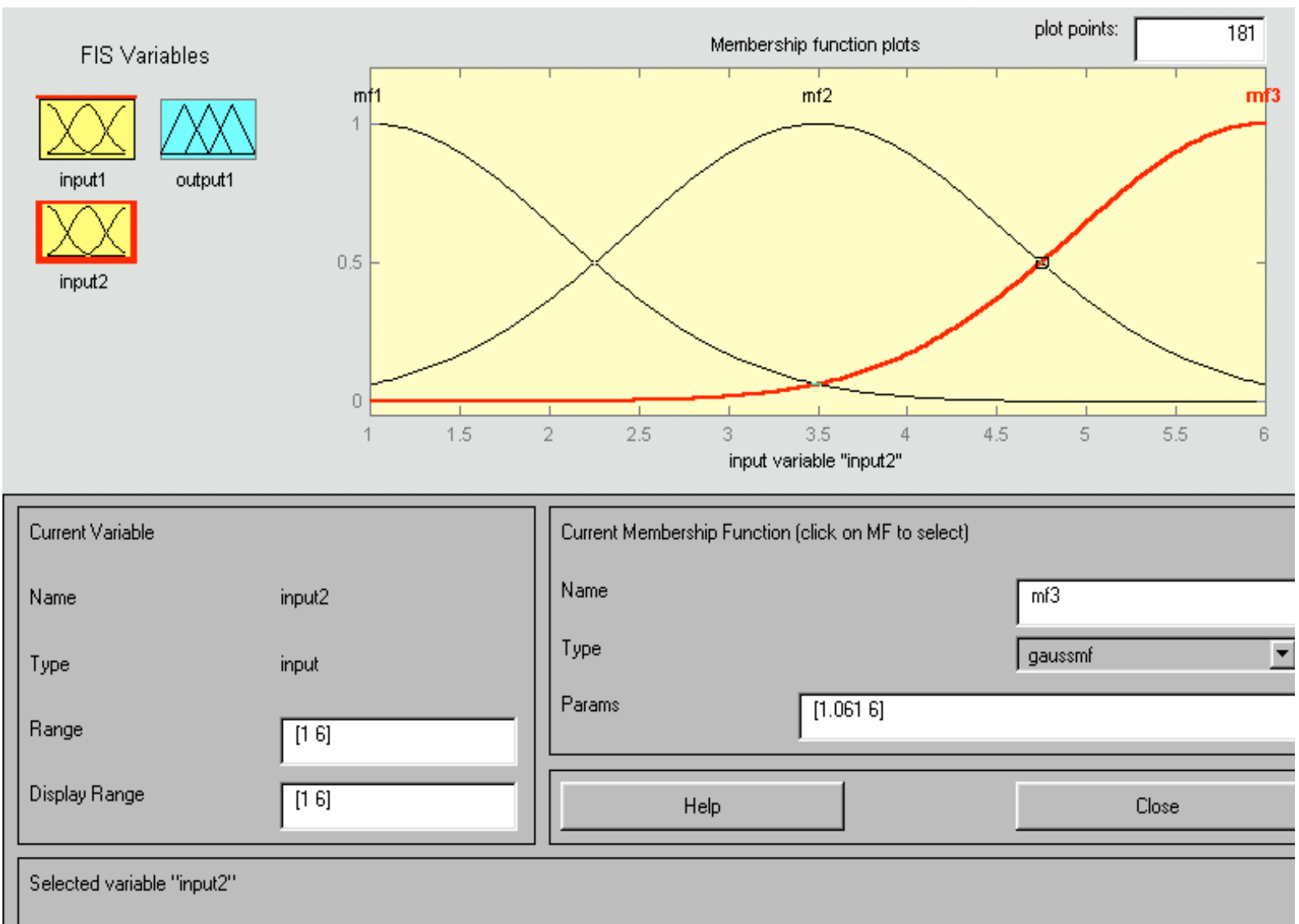

Figura 10 - Pelo final da entrada 2 do sistema nebuloso de Mamdami 
NFIS Editor: Untitled

File Edit View

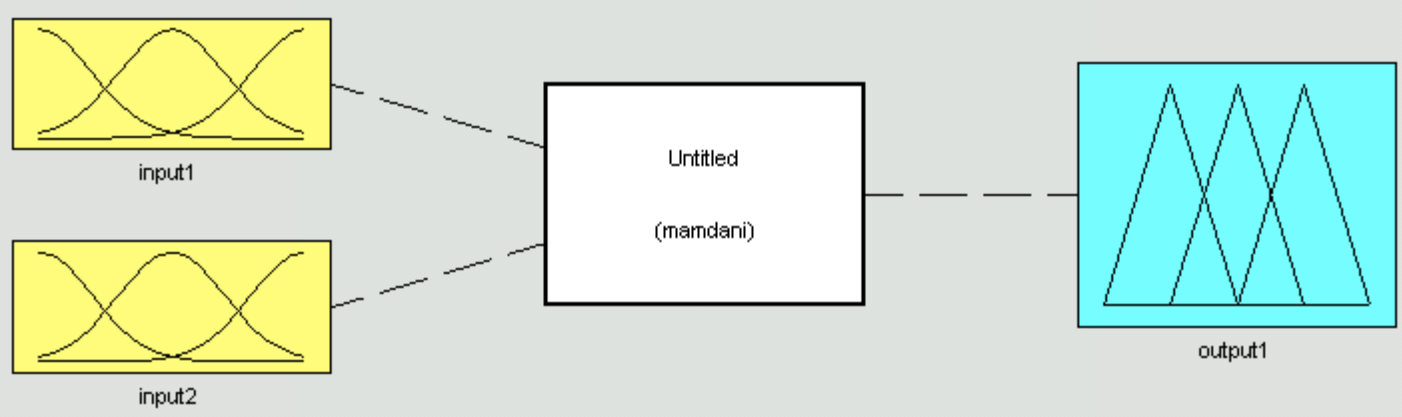

\begin{tabular}{|c|c|c|c|c|}
\hline FIS Name: & Untitled & & FIS Type: & mamdani \\
\hline And method & prod & $\nabla$ & \multirow{4}{*}{$\begin{array}{l}\text { Current Variable } \\
\text { Name } \\
\text { Type } \\
\text { Range }\end{array}$} & \\
\hline Or method & \begin{tabular}{|l}
$\min$ \\
prod \\
Custom... \\
\end{tabular} & & & \\
\hline Implication & prod & $\nabla$ & & \\
\hline Aggregation & $\max$ & $\nabla$ & & \\
\hline Defuzzification & \begin{tabular}{|l|} 
centroid \\
\end{tabular} & $\nabla$ & Help & Close \\
\hline
\end{tabular}

Changing agglMethod to "max"

Figura 11 - Definição do sistema nebuloso de Mamdami

NFIS Editor: Untitled

File Édit View

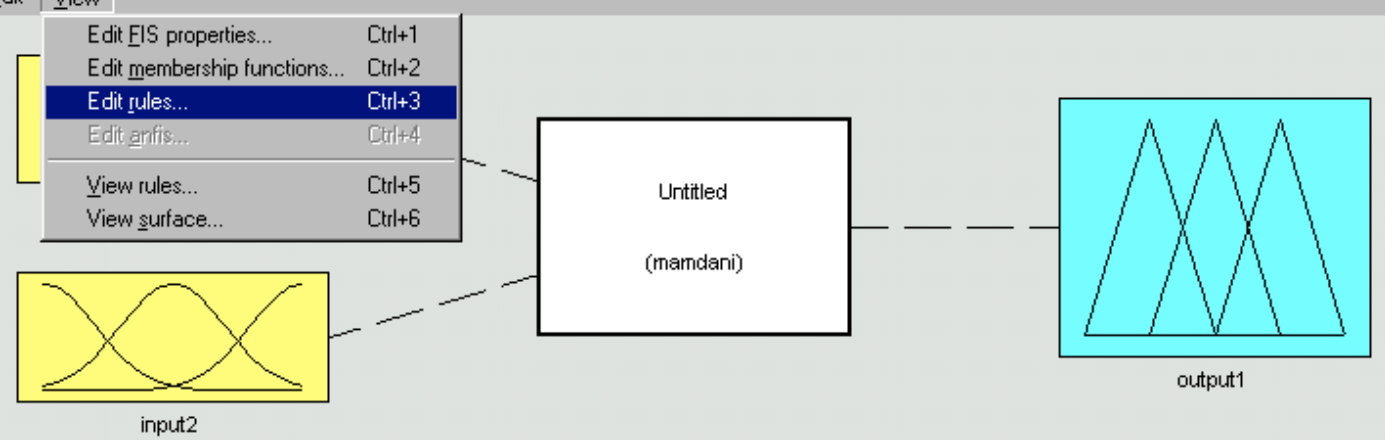

\begin{tabular}{|c|c|c|c|c|}
\hline FIS Name: & Untitled & & FIS Type: & mamdani \\
\hline And method & prod & $\nabla$ & Current Variable & \\
\hline Or method & $\max$ & $\nabla$ & Name & \\
\hline & & & Type & \\
\hline Implication & prod & $\nabla$ & & \\
\hline Aggregation & $\max$ & $\nabla$ & Riange & \\
\hline Defuzzification & centroid & $\nabla$ & Help & Close \\
\hline
\end{tabular}

Changing aggMethod to "max"

Figura 12 - Editor de regras do sistema nebuloso de Mamdami 
ARule Editor: Untitled

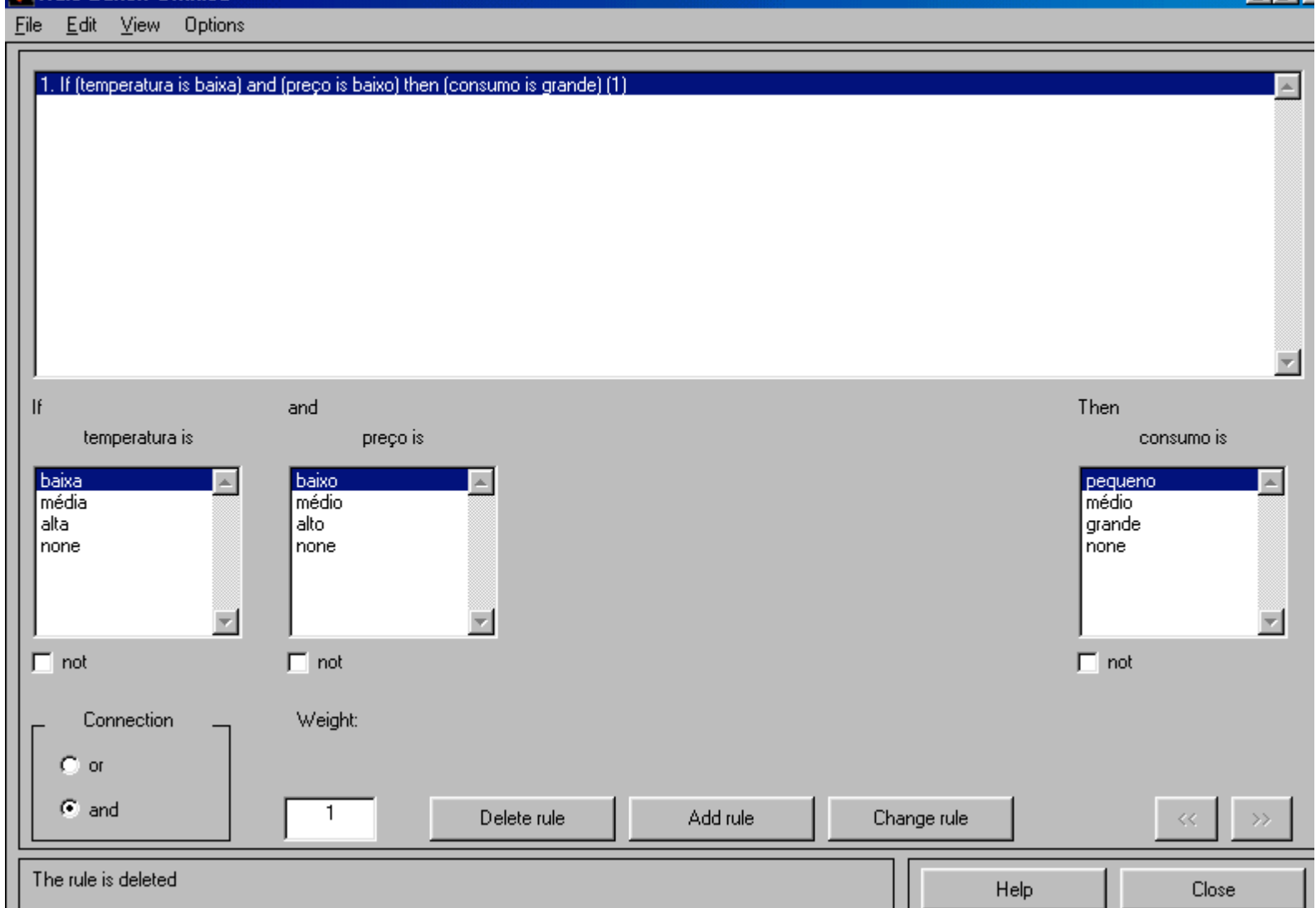

Figura 13 - Regra 1 do sistema nebuloso de Mamdami

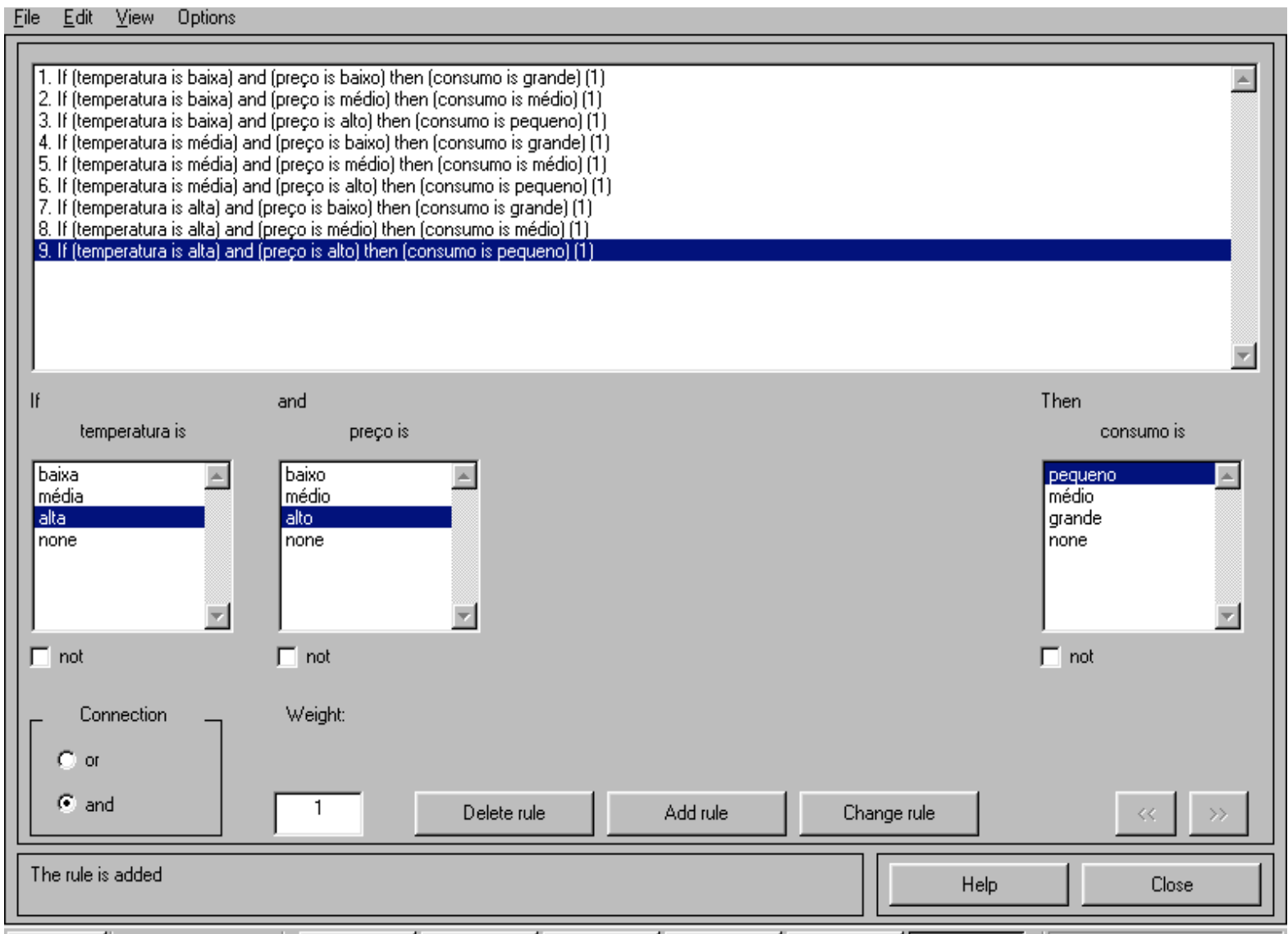

Figura 14 - Regras do sistema nebuloso de Mamdami 


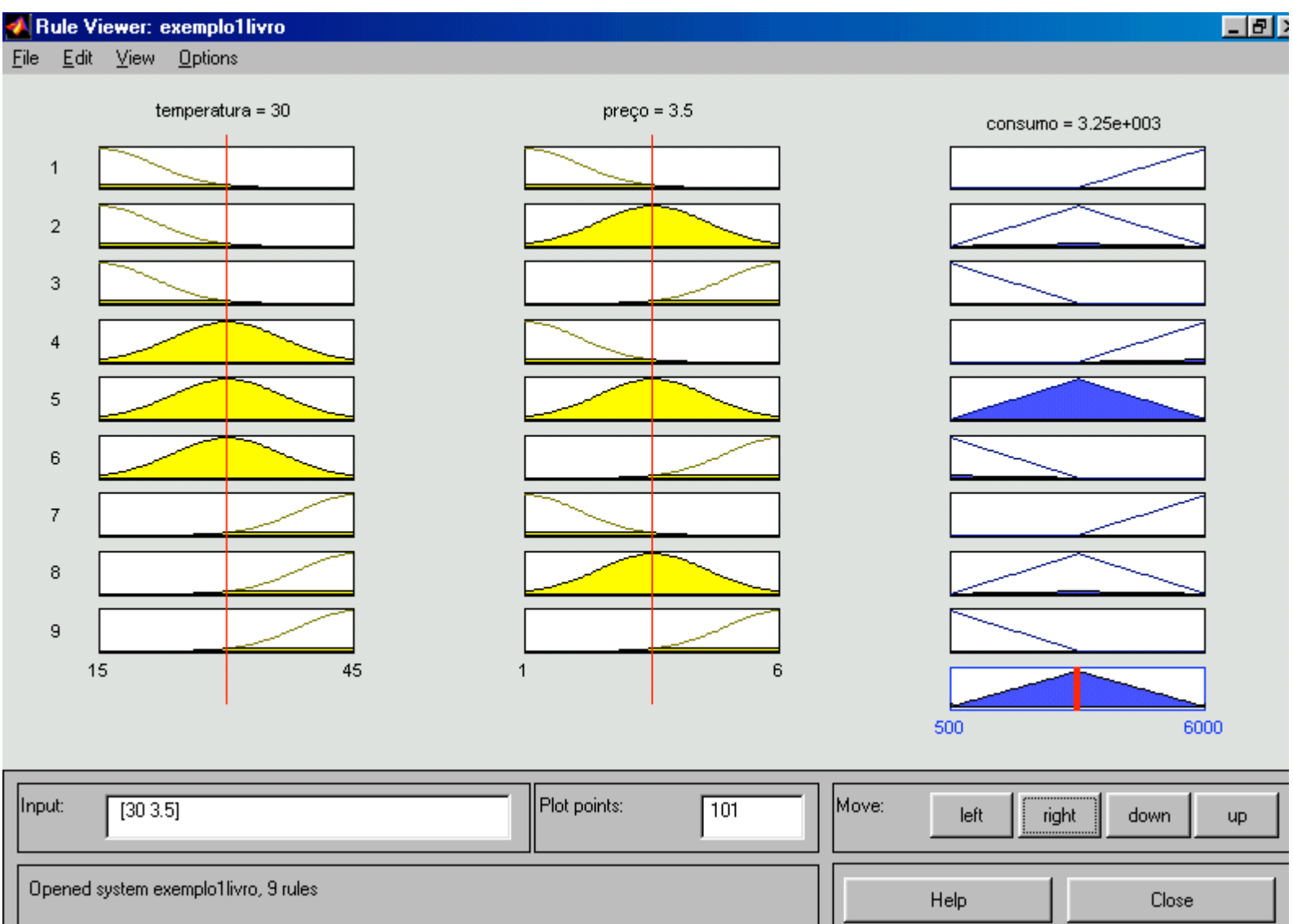

Figura 15 - Visualização da previsão do sistema nebuloso de Mamdami

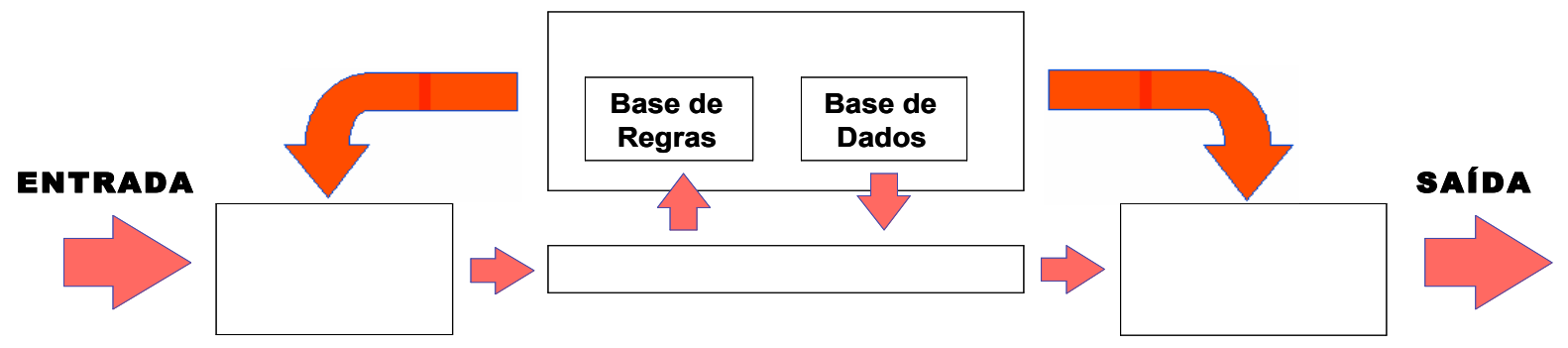

Figura 16 - Blocos principais de um sistema de inferência nebuloso 

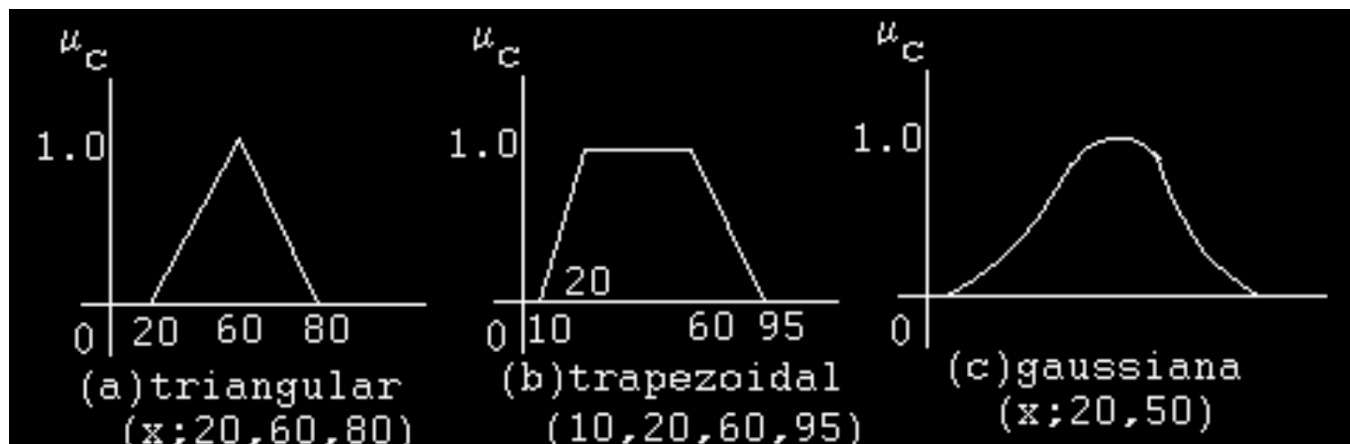

$(x ; 20,60,80)$

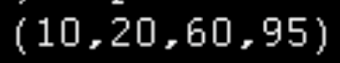

(c)gaussiana

$(x ; 20,50)$
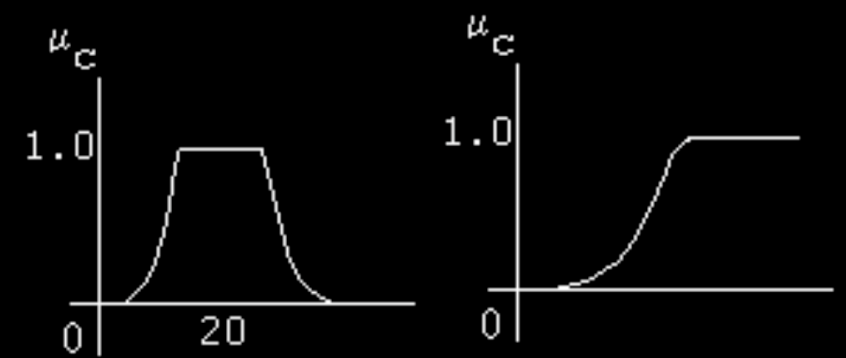

(d) sino

$(\mathrm{x} ; 20,4,5)$

(e) sigmoidal

Figura 17 - Funções utilizadas para nebulização

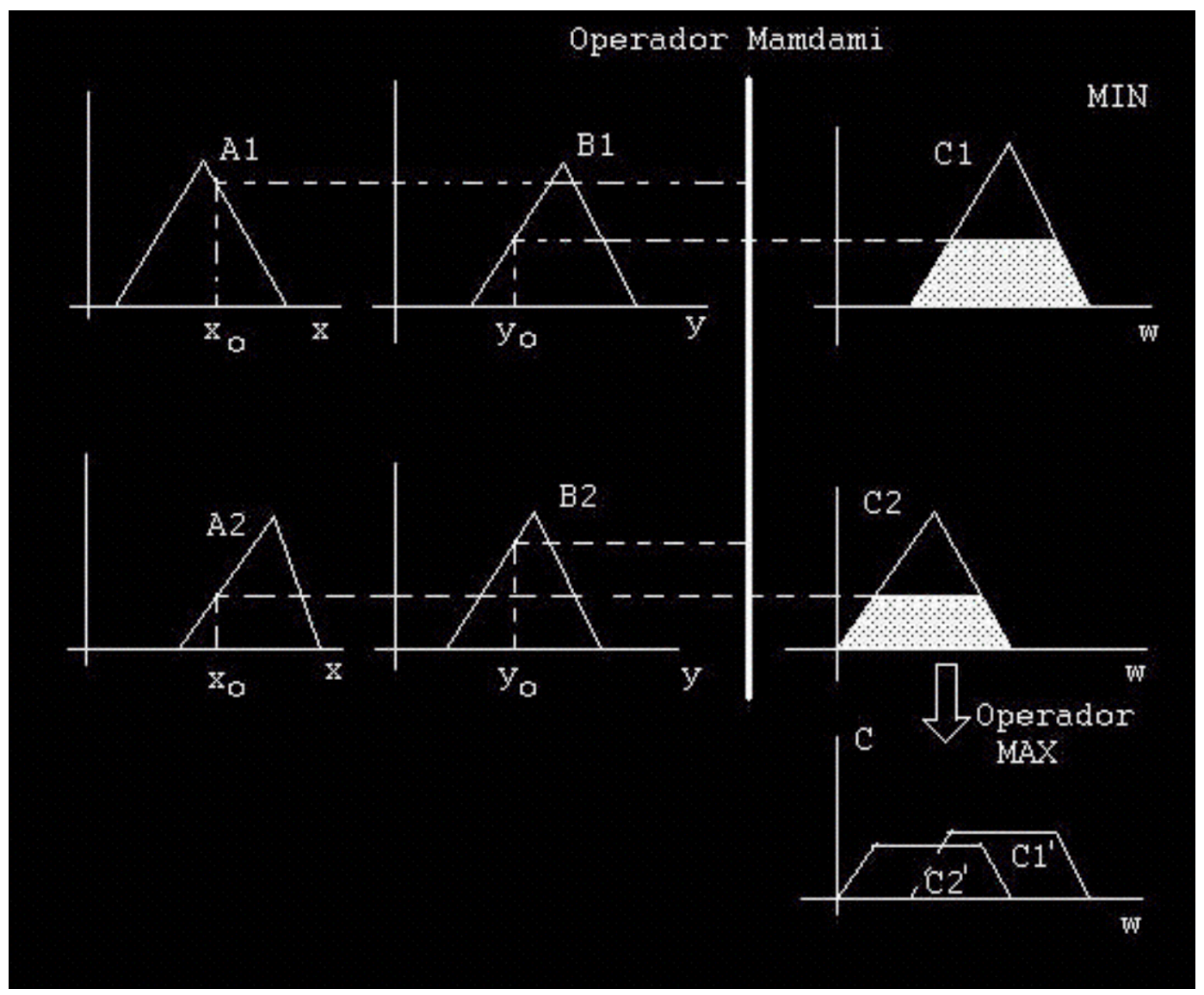

Figura 19 - Raciocínio Nebuloso de Mamdami 


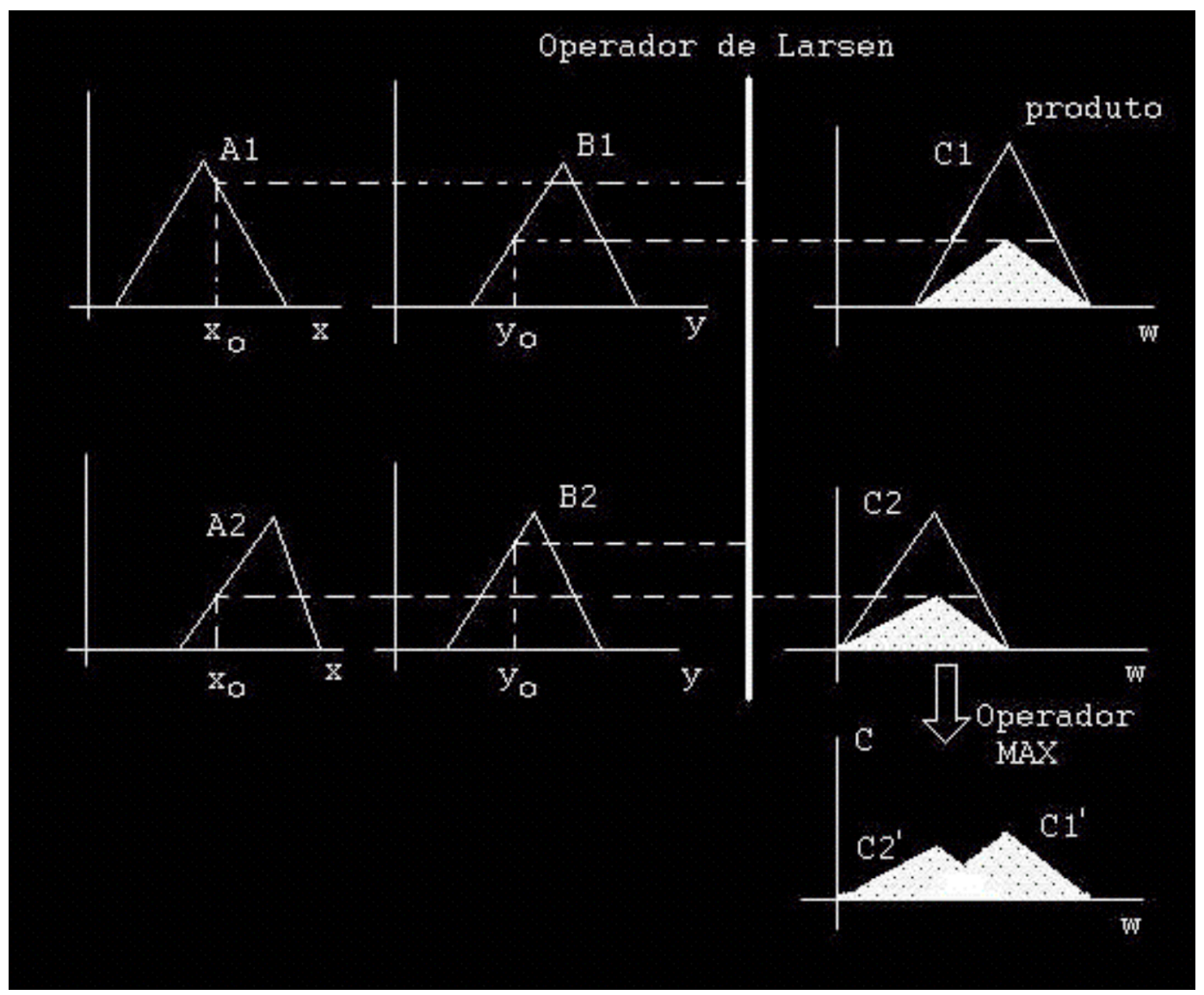

Figura 20 - Raciocínio Nebuloso de Larsen

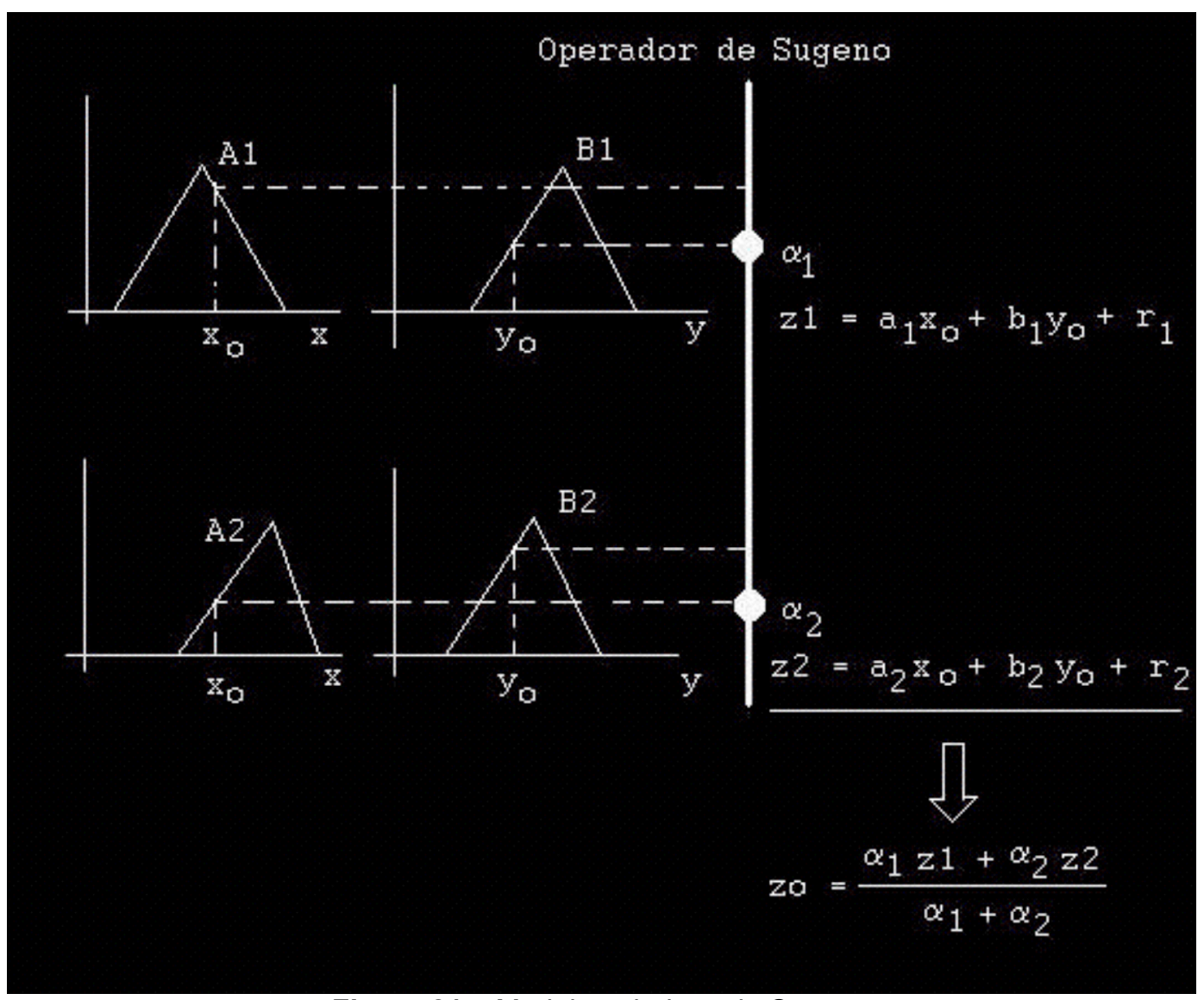

Figura 21 - Modelo nebuloso de Sugeno 


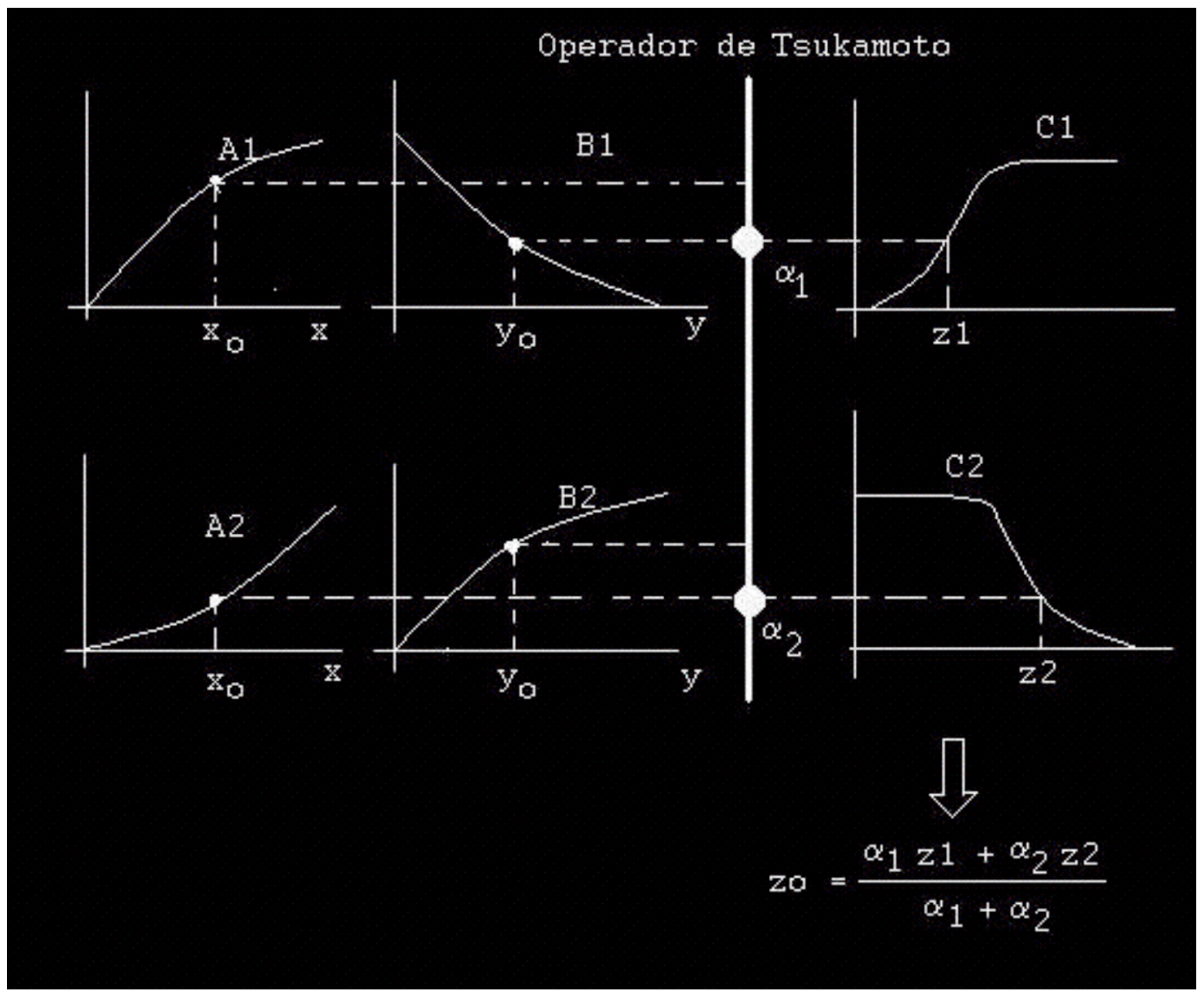

Figura 22 - Modelo nebuloso de Tsukamoto

\section{Consolidação das Informações Retiradas do Banco de Dados}

\section{Situação}

Adimplente $72,19 \% 25678$ Inadimplente27,81\% 9891

\begin{tabular}{ccccccc} 
Tipo de Profissão & \multicolumn{2}{c}{ Adimplente } & \multicolumn{2}{c}{ Inadimplente } \\
Assalariado36,55\% & 13002 & $25 \%$ & 8960 & $11 \%$ & 4042 \\
Autônomo18,09\% & 6433 & $12 \%$ & 4364 & $6 \%$ & 2069 \\
Func. Públicd 6,69\% & 5937 & $12 \%$ & 4377 & $4 \%$ & 1560 \\
Aposentado28,67\% & 10197 & $22 \%$ & 7977 & $6 \%$ & 2220
\end{tabular}

\section{Salário (R\$)}

Menor que $500,001,64 \% 4141$ De 500,00 a $800,020,10 \% 9638$ De 800,00 a $1.100,00,46 \% 8343$ De $1.100,00$ a $1.400,02,84 \% 4566$ Maior que $1.400,021,97 \% 8881$
Adimplente Inadimplente

$8 \% \quad 2815 \quad 4 \% \quad 1326$

$19 \% \quad 6660 \quad 8 \% \quad 2978$

$\begin{array}{llll}17 \% & 6034 & 6 \% & 2309\end{array}$

$10 \% \quad 3401 \quad 3 \% \quad 1165$ $\begin{array}{llll}19 \% & 6768 & 6 \% & 2113\end{array}$

\begin{tabular}{|c|c|c|c|c|c|}
\hline Estado Civil & & \multicolumn{2}{|c|}{ Adimplente } & \multicolumn{2}{|c|}{ Inadimplente } \\
\hline Solteiro $31,65 \%$ & 11259 & $21 \%$ & 7607 & $10 \%$ & 3652 \\
\hline Casado $57,00 \%$ & 20276 & $44 \%$ & 15488 & $13 \%$ & 4788 \\
\hline Divorciado 6,69\% & 2378 & $4 \%$ & 1515 & $2 \%$ & 863 \\
\hline Viúvo 4,66\% & 1656 & $3 \%$ & 1068 & $2 \%$ & 588 \\
\hline \multicolumn{2}{|l|}{ Idade (anos) } & \multicolumn{2}{|c|}{ Adimplente } & \multicolumn{2}{|c|}{ Inadimplente } \\
\hline Menor que $304,29 \%$ & 5083 & $9 \%$ & 3292 & $5 \%$ & 1791 \\
\hline Entre 30 e $423,23 \%$ & 8263 & $16 \%$ & 5612 & $7 \%$ & 2651 \\
\hline Entre 40 e $524,97 \%$ & 8881 & $18 \%$ & 6314 & $7 \%$ & 2567 \\
\hline Entre 50 e $6019,41 \%$ & 6905 & $15 \%$ & 5311 & $4 \%$ & 1594 \\
\hline Maior que $6018,10 \%$ & 6437 & $14 \%$ & 5149 & $4 \%$ & 1288 \\
\hline \multicolumn{2}{|c|}{ Prestação / Salário (\%) } & \multicolumn{2}{|c|}{ Adimplente } & \multicolumn{2}{|c|}{ Inadimplente } \\
\hline Menor que $102,16 \%$ & 4327 & $9 \%$ & 3203 & $3 \%$ & 1124 \\
\hline Entre 10 e $120,20 \%$ & 7186 & $15 \%$ & 5313 & $5 \%$ & 1873 \\
\hline Entre 15 e $230,26 \%$ & 10762 & $21 \%$ & 7631 & $9 \%$ & 3131 \\
\hline ntre 20 e $252,30 \%$ & 7932 & $16 \%$ & 5533 & $7 \%$ & 2399 \\
\hline Maior que $2515,07 \%$ & 5362 & $11 \%$ & 3998 & $4 \%$ & 136 \\
\hline
\end{tabular}

Tabela 1 - Consolidação das Informações Retiradas do Banco de Dados 


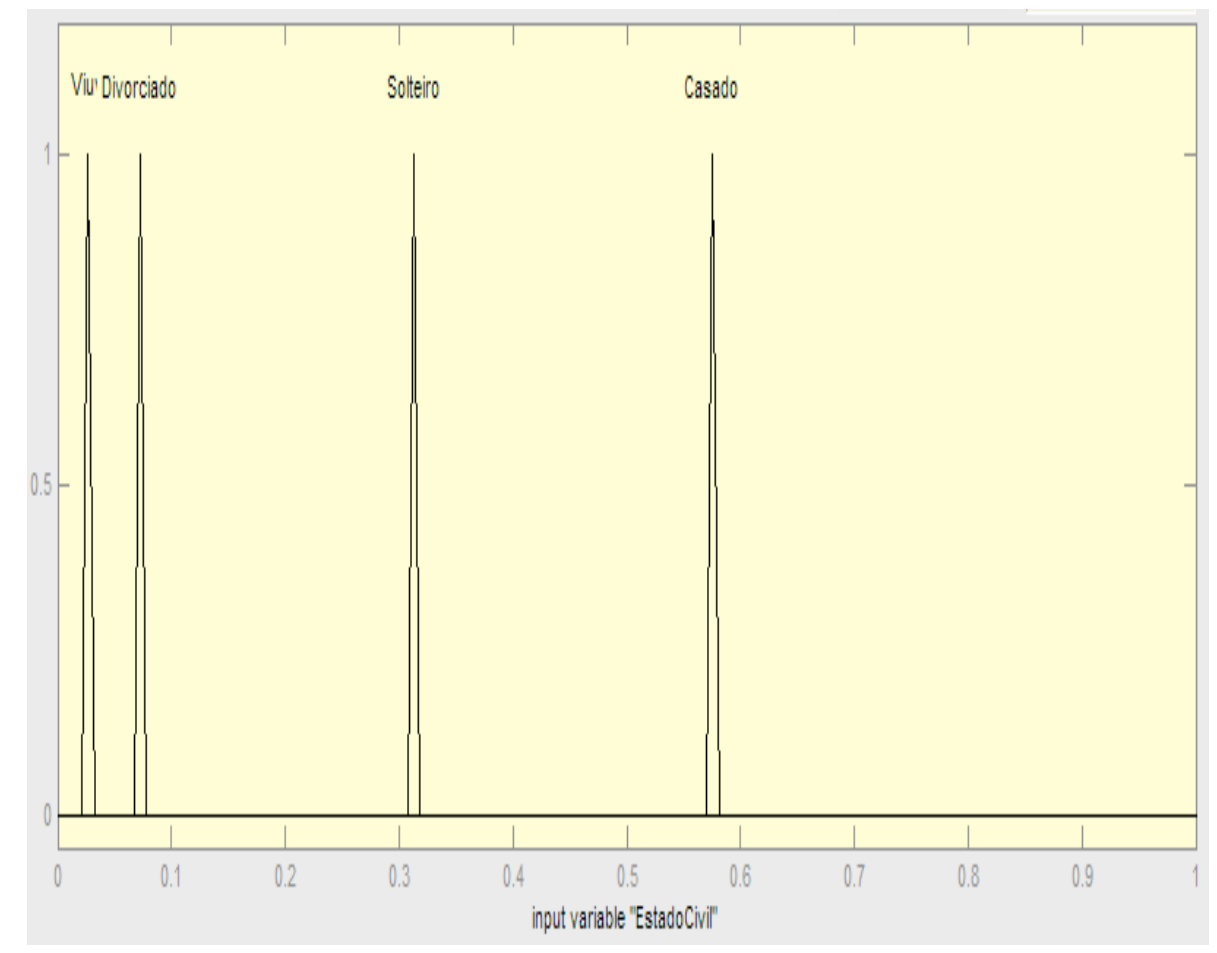

Figura 23 - Função de pertinência para Estado Civil

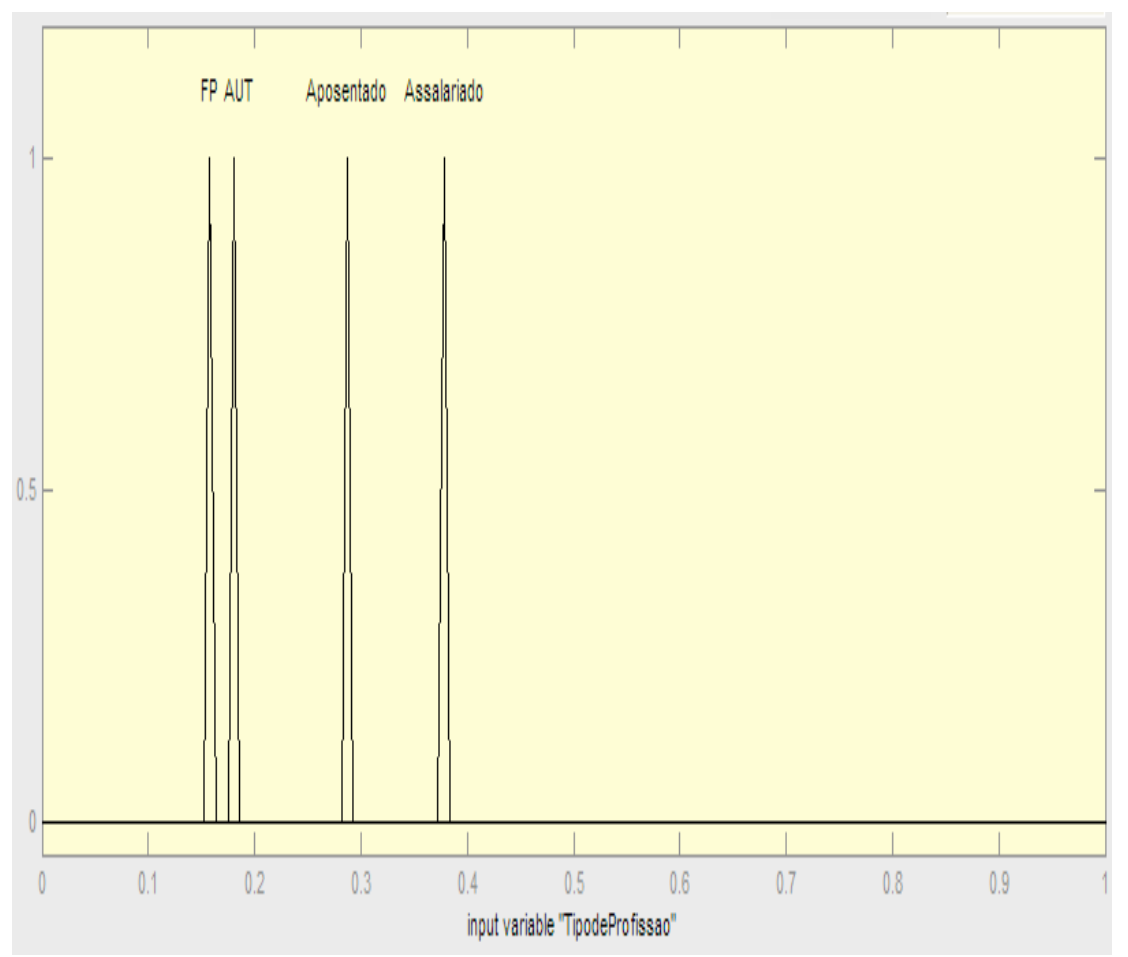

Figura 24 - Função de pertinência para Tipo de Profissão 


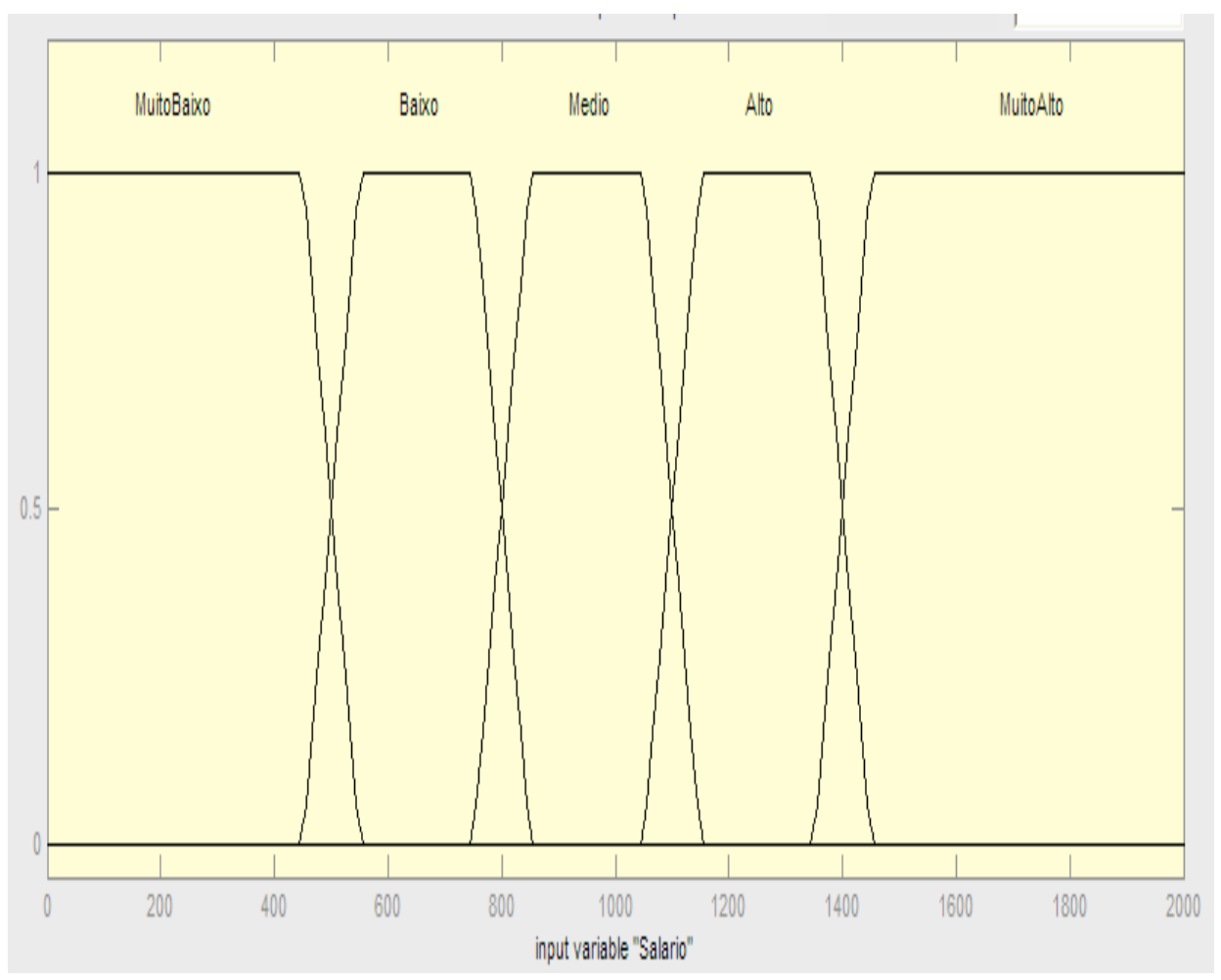

Figura 25 - Função de pertinência para Salário

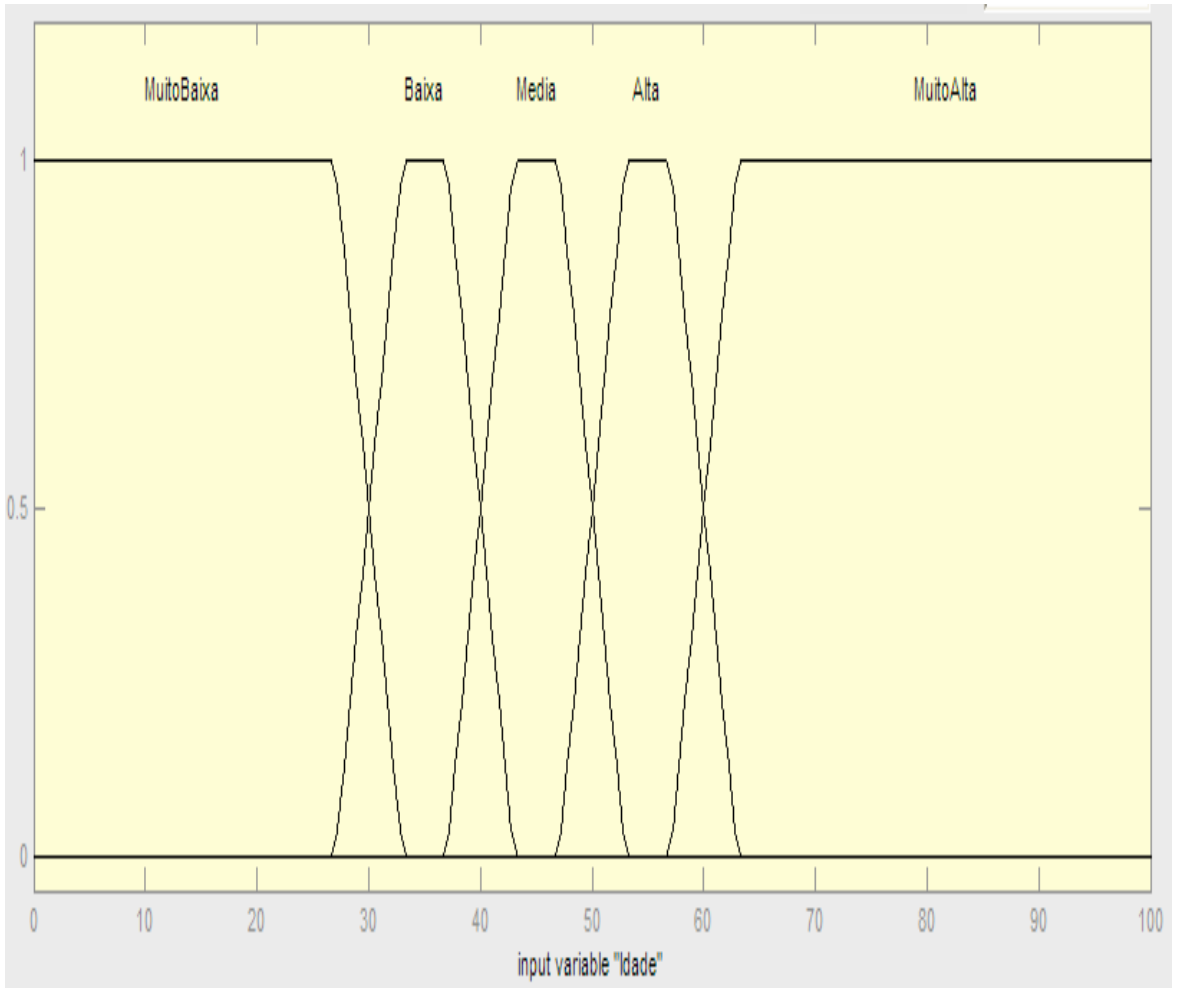

Figura 26 - Função de pertinência para Idade 


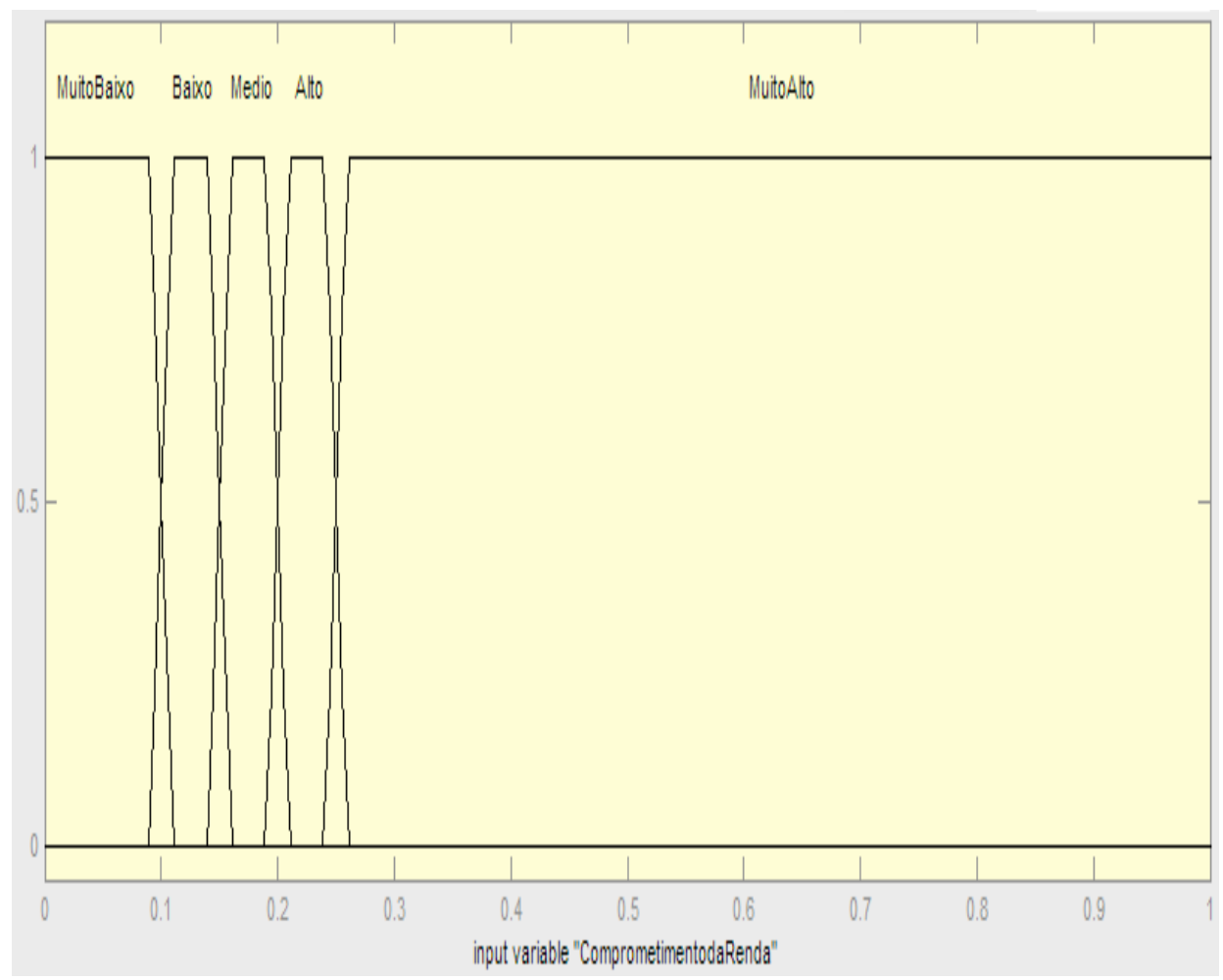

Figura 27 - Função de pertinência para Comprometimento da Renda

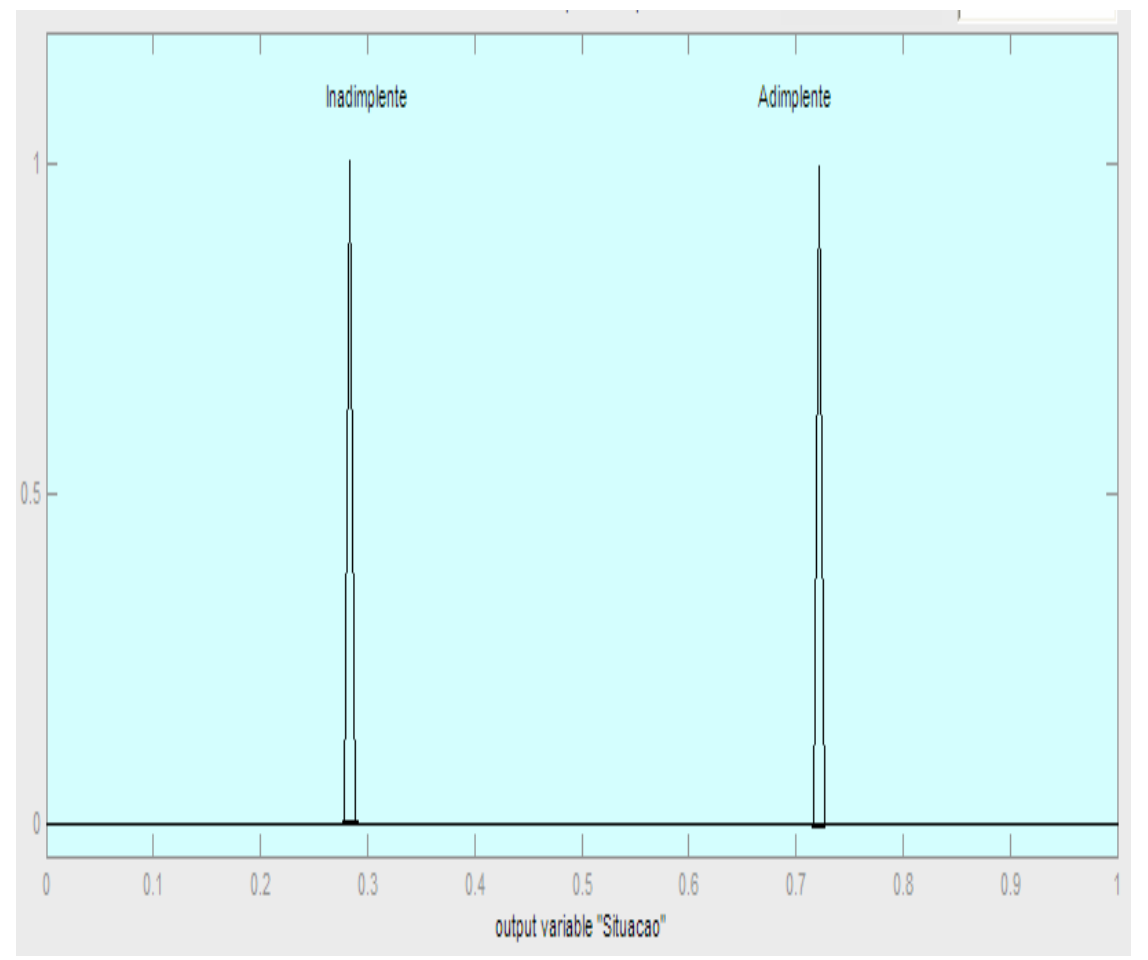

Figura 28 - Função de pertinência para Situação 